Soto-Saravia, R. A., C. M. Garrido-Cayul, J. Avaria-Llautureo, A. Benítez-Mora, C. E. Hernández, and M. González-Suárez. 2021. Threatened neotropical birds are big, ecologically specialized, and found in less humanized refuge areas. Avian Conservation and Ecology $16(2): 18$. https://doi. org/10.5751/ACE-01948-160218

Copyright (C) 2021 by the author(s). Published here under license by the Resilience Alliance.

Research Paper

\title{
Threatened neotropical birds are big, ecologically specialized, and found in less humanized refuge areas
}

Ricardo A. Soto-Saravia ${ }^{1,2}$, Carla M. Garrido-Cayul ${ }^{2}$, Jorge Avaria-Llautureo $^{3}$, Alfonso Benítez-Mora ${ }^{4}$, Cristián E. Hernández ${ }^{2,5}$ and $^{2}$ Manuela González-Suárez ${ }^{1}$

${ }^{1}$ Ecology and Evolutionary Biology, School of Biological Sciences, University of Reading, Whiteknights, Reading. United Kingdom, ${ }^{2}$ Laboratorio de Ecología Evolutiva y Filoinformática. Departamento de Zoología, Facultad de Ciencias Naturales y Oceanográficas, Universidad de Concepción. Concepción, Chile, ${ }^{3}$ Centro de Estudios Avanzados en Zonas Áridas, CEAZA, Coquimbo, Chile, ${ }^{4}$ Universidad Bernardo O'Higgins, Centro de Investigación en Recursos Naturales y Sustentabilidad (CIRENYS), Santiago, Chile, ${ }^{5}$ Universidad Católica de Santa María, Arequipa, Perú. Universidad Católica de Santa María, Arequipa, Perú

\begin{abstract}
Ecosystem anthropization is a main driver of biodiversity loss, but not all species are equally susceptible. Understanding and preventing biodiversity loss is particularly important in rapidly changing and biodiversity-rich areas like the Neotropics and requires exploring the role of both intrinsic and extrinsic vulnerability drivers. Here, we test how multiple potential intrinsic and extrinsic factors explain vulnerability to extinction in neotropical birds to provide a first insight into what makes these species susceptible to extinction and how they are responding to anthropization. Our analyses included data for 2268 neotropical birds. We characterized extinction risk based on the IUCN Red List categorization and tested the predictive value of seven intrinsic and four extrinsic variables using Bayesian MCMC Phylogenetic Generalized Least-Squares (PGLS) models. As hypothesized, we found higher intrinsic vulnerability to extinction among bigger and more specialized species which have low reproductive output and occupy smaller distribution ranges. Extrinsic drivers were also relevant predictors with more threatened species overlapping largely areas with fewer human activities (lower night light levels and lower human population densities). Our results show that the extinction risk of neotropical birds is correlated with both intrinsic and extrinsic factors. Intrinsic vulnerabilities were as expected associated with narrower, specialized niches and slower life histories. However, risk was not higher in more humanized environments, but instead more at-risk species were found in less disturbed areas that we suggest may represent refuges for birds that previously occurred in wider ranges and have now been excluded from the more anthropized regions. Our results contribute to our understanding of vulnerability predictors in birds and provide a first evaluation of neotropical birds that highlights the complex relationship between human pressure and biodiversity loss.
\end{abstract}

\section{Les oiseaux néotropicaux menacés sont de grande taille, écologiquement spécialisés, et présents dans des zones protégées moins peuplées}

RÉSUMÉ. L'anthropisation de l'écosystème est un pilote majeur de la perte de la biodiversité, mais toutes les espèces n'y sont pas autant susceptibles. Il est particulièrement important de comprendre et de prévenir la perte de la biodiversité dans des zones en transformation rapide et riches en biodiversité comme les régions néotropicales. Il faut pour cela explorer le rôle des pilotes intrinsèques et extrinsèques de la vulnérabilité. Nous testons ici la manière dont de multiples facteurs intrinsèques et extrinsèques potentiels explique la vulnérabilité à l'extinction des oiseaux néotropicaux pour fournir un premier aperçu des raisons pour lesquelles ces espèces sont menacées d'extinction et de leur réaction à l'anthropisation. Nos analyses incluaient des données portant sur 2268 oiseaux néotropicaux. Nous avons caractérisé le risque d'extinction en fonction du classement sur la liste rouge de l'UICN et testé la valeur prédictive de sept variables intrinsèques et de quatre variables extrinsèques en utilisant des modèles MCMC bayésiens de Régression phylogénétique des moindres carrés généralisés (PGLS). Selon les hypothèses utilisées, nous avons constaté une vulnérabilité intrinsèque supérieure à l'extinction parmi les espèces plus grandes et plus spécialisées dont le rendement reproductif est faible et qui occupent des territoires de répartition moins étendus. Les pilotes extrinsèques étaient également des indicateurs pertinents, puisque davantage d'espèces menacées occupent des zones de moindre activité humaine (aux niveaux de luminosité nocturne faibles et à la densité de population humaine réduite). Nos résultats indiquent que le risque d'extinction des oiseaux néotropicaux est corrélé à la fois à des facteurs intrinsèques et extrinsèques. Les vulnérabilités étaient comme prévu associées à des niches plus étroites et spécialisées et à des cycles biologiques plus lents. Toutefois, le risque n'était pas plus élevé dans les environnements plus humanisés, mais davantage d'espèces à risque étaient présentes dans des zones moins perturbées, qui selon nous, pourraient représenter des refuges pour des oiseaux qui occupaient auparavant des territoires plus étendus, mais qui ont maintenant été exclus des régions les plus anthropisées. Nos résultats contribuent à notre compréhension des indicateurs de vulnérabilité des oiseaux et fournissent une première évaluation des oiseaux néotropicaux qui met en évidence la relation complexe entre la pression humaine et la perte de biodiversité.

Key Words: anthropic effect; biodiversity loss; conservation; comparative methods; extrinsic features; intrinsic features; 


\section{INTRODUCTION}

The anthropization of the world's ecosystems with overexploitation of resources and extensive alteration and fragmentation of natural habitats is leading to widespread biodiversity loss (McKinney 2006, Barnosky et al. 2012, Green et al. 2019). According to the IUCN, since 1750, more than 900 species of plants and animals, had become extinct, and more than 35000 are now categorized as threatened (IUCN 2020). However, not all regions are equally affected. The Neotropics have the lowest Ecological Human Footprint values globally (EHF, sensu Sanderson et al. 2002) and contain some of the largest remaining pristine natural areas (Pichorim et al. 2016, Rull and VegasVilarrúbia 2017, Weinzettel et al. 2018). However, many of these areas are being rapidly transformed leading to habitat loss and fragmentation which threatens biodiversity (Tabarelli et al. 2004, Ribeiro et al. 2009). The Neotropics have high levels of biodiversity and endemism (Orme et al. 2005, Harrison and Noss 2017), including many potentially vulnerable tropical species (Baiser et al. 2012, Durán et al. 2020). Unfortunately, we have a limited understanding of what factors predict extinction risk in this area, even among well-studied groups like birds. Rapidly expanding threats and the remaining high levels of biodiversity make it critical and urgent to identify the key drivers of extinction, so we can define more effective conservation policies and actions to prevent further defaunation.

Extinction does not occur randomly, but risk is affected by a combination of external impacts, often anthropic, and intrinsic vulnerabilities (Davidson et al. 2012, González-Suárez et al. 2013). Intrinsic vulnerability reflects traits and characteristics that make some individuals, populations, and taxa more susceptible to population declines and limit their capacity to recover. For example, the size of a species geographical range is a key vulnerability factor and is one of the criteria for listing species as threatened in the IUCN Red List (IUCN 2020) and is negatively associated with extinction risk (Lee and Jetz 2010, Davidson et al. 2012, Gonzalez-Suarez et al. 2013). The smaller the range, the higher the probability that disturbance and environmental change will affect the species entirely leading to global extinction, and also smaller ranges generally mean smaller total population size which also increases risk (Gaston and Blackburn 2000). However, how range size influences vulnerability depends on different species' traits as well. For example, susceptibility is particularly noticeable for specialist species (Brown and Maurer 1989) which have more limited niche requirements (Correll et al. 2016), often have smaller population sizes and more limited dispersal capabilities (Colles et al. 2009), and are more affected by edge effects than generalists (Sodhi et al. 2009).

Previous studies have identified several of these general vulnerability traits in vertebrates including: large body size (Gaston and Blackburn 1995), high energetic expenditure rates (Geiser and Turbill 2009), slow reproduction associated with lower gestation period, delayed sexual maturity and lower fecundity (Fisher et al. 2001), reduced intraspecific trait variability (González-Suárez and Revilla 2013), and niche specialization (Sodhi et al. 2009). However, intrinsic characteristics account for only a portion of the variation in extinction risk (Purvis et al. 2005). Anthropogenic factors such as human density, agricultural and urban land use, species exploitation, introduced species including those associated with disease, and anthropogenic climate change are strongly associated with contemporary extinction risk (Forester and Machlist 1996). For example, McKee et al. (2013), found that the relative number of threatened species per unit area was best explained by human population density, the proportion of agricultural land used, and degree of endemism. Recently, some authors have called for also considering variables like artificial night light (Chepesiuk 2009, Dominoni 2017) that changes with land use and human accessibility. Many studies have explored the impacts of artificial light on individual organisms, but studies on the general impacts across populations, communities, and ecosystems remain rare (Gaston et al. 2015). In addition to capturing other impacts, artificial night light intensity can itself be a threat. Night light can be six times higher in cities than in suburban and rural areas (Davies et al. 2013, Isaksson 2018), threatening biological processes associated with natural moonlight cycles (KronfeldSchor et al. 2013, Dominoni 2017) possibly altering natural circadian rhythms (Davies et al. 2012, Aubé et al. 2013), and can pose a threat to nocturnally migrating birds (Cabrera-Cruz et al. 2018, Cabrera-Cruz et al. 2019, Horton et al. 2019).

While there is evidence that both intrinsic and extrinsic factors are important, previous studies of extinction risk in birds have generally addressed these separately, which limits our ability to recognize their relative importance. There are some notable exceptions that considered both drivers but these either focused on particular threats or limited the analyses to relatively simple two-variable models (Bennett and Owens 1997, Wang et al. 2017). Here we present a comprehensive analysis evaluating the individual and combined effects of multiple intrinsic and extrinsic factors on the extinction risk of neotropical birds. Extinction risk or conservation status of neotropical birds have been studied before, but previous work primarily focused on specific species or groups (e.g., Olah et al. 2016, Lees et al. 2021), localities (e.g., Stouffer et al. 2006, Lees and Peres 2008, Devenish et al. 2020), or a few traits and factors (e.g., Lees and Peres 2008, Ferretti 2019, Prieto-Torres et al. 2021). Collectively, previous work has provided useful insights, but only by expanding the taxonomic and geographic scales and testing diverse intrinsic and extrinsic factors can we hope to gain a more holistic picture of generalized patterns.

Based on previous studies on other regions and taxa, we predict larger species that are ecologically specialized and that have lower reproductive rates will have higher risk of extinction. We also expect risk to increase for species in areas with higher human densities, higher levels of artificial night light, and more human land use changes. However, we note that the opposite pattern has been found in mammals with threatened species occurring in more natural areas likely because they become restricted to these refuges after being locally extirpated from modified regions (Polaina et al 2018). Thus, an alternative prediction of lower risk associated with impacted areas was also considered. We focus on birds because they are a widespread group of conservation interest and data are generally available for many species.

\section{METHODS}

\section{Data}

We defined endemic neotropical birds as those with $>80 \%$ of their distribution range located within the Neotropics region described 
Table 1. Description and reference sources of the intrinsic and extrinsic predictors analysed in this study.

\begin{tabular}{|c|c|c|c|}
\hline Variable Type & Variable Name & Description & Reference \\
\hline \multirow[t]{6}{*}{ Intrinsic } & Body Size ${ }^{\dagger}$ & $\begin{array}{l}\text { size measured in } \mathrm{cm} \text { from the beak to the longest point of the bird, including tail } \\
\text { and legs. }\end{array}$ & (Billerman et al. 2020) \\
\hline & $\begin{array}{l}\text { Maximum Clutch } \\
\text { Size }^{\dagger}\end{array}$ & Maximum observed number eggs in a single reproductive event & (Billerman et al. 2020) \\
\hline & Neotropical Area ${ }^{\dagger}$ & $\begin{array}{l}\text { Distribution range area in } \mathrm{km} 2 \text { within the neotropical Ecoregion boundaries } \\
\text { defined by (Olson et al. 2001). }\end{array}$ & (BirdLife International 2020) \\
\hline & Diet Breath & $\begin{array}{l}\text { Levin's standardized index (Levins 1968) describing trophic niche breadth } \\
\text { calculated using data on dietary composition across } 10 \text { categories. The index } \\
\text { ranges from } 0 \text { to } 1 \text {, where } 0 \text { indicates complete specialization - consumption of a } \\
\text { single diet category. }\end{array}$ & (Wilman et al. 2014) \\
\hline & Habitat Breadth & $\begin{array}{l}\text { Levin's standardized index (Levins 1968) describing habitat breadth based on } \\
\text { fourteen biomes. The index ranges from } 0 \text { to } 1 \text {, where } 0 \text { indicates complete } \\
\text { specialization - present in a single habitat category. }\end{array}$ & (Olson et al. 2001) \\
\hline & $\begin{array}{l}\text { Foraging Strategies } \\
\text { Breadth }\end{array}$ & $\begin{array}{l}\text { Levin's standardized index (Levins 1968) describing foraging strategy breadth } \\
\text { based on nine ecategories describing types of foraging substrates. The index } \\
\text { ranges from } 0 \text { to } 1 \text {, where } 0 \text { indicates complete specialization - using a single } \\
\text { foraging substrate. }\end{array}$ & (Wilman et al. 2014) \\
\hline \multirow[t]{4}{*}{ Extrinsic } & Natural Proportion & $\begin{array}{l}\text { Proportion of the neotropical distribution range area overlapping with areas } \\
\text { described as: "Wild forests", "Sparse trees" or "Barren" categories" in the } \\
\text { anthropogenic regions of the world map }\end{array}$ & (Ellis \& Ramankutty 2008) \\
\hline & Night Light ${ }^{\dagger \dagger}$ & $\begin{array}{l}\text { Arithmetic mean of the light intensity levels within the neotropical distribution } \\
\text { range area. }\end{array}$ & (NOAA 2017) \\
\hline & Human ${ }^{\dagger t}$ Population & $\begin{array}{l}\text { Arithmetic mean of the human population density based on the Gridded } \\
\text { Population of the World V3. }\end{array}$ & (CIESIN 2000) \\
\hline & Human Footprint ${ }^{\dagger *}$ & $\begin{array}{l}\text { Arithmetic mean of the Global Human Footprint. We used V2 which was created } \\
\text { from nine global data set layers covering several spectra of human impact and } \\
\text { normalized by biome realm. }\end{array}$ & (WCS \& CIESIN 2005) \\
\hline
\end{tabular}

by Olson et al. (2001) and classified as Neotropical by The Cornell Lab of Ornithology (Billerman et al. 2020). In addition, we excluded migratory species that have their entire breeding distribution area outside the Neotropics. To estimate distribution overlap, we used range data from Birdlife International (BirdLife International 2020) using polygons classified in the following categories for origin: Native and Vagrant, presence: Extant and Probably Extant, and season: Resident, Breeding Season, Nonbreeding Season, and Passage. All spatial data were analyzed using a Cylindrical Equal Area projection. Details on the collection and preparation of the range data are in Section 1 of Appendix 1.

We compiled information on potential intrinsic and extrinsic drivers or predictors of extinction risk for the identified endemic neotropical birds. Intrinsic drivers were represented by the variables: mean adult body size, maximum clutch size, and three descriptors of specialization based on diet, habitat, and foraging strategies breadths (Table 1). Breadths were calculated using standardized Levin's indices (Levins 1968) defined as $B^{\prime}=B-1 / k-1$, where is the number of possible resources (diet, habitat, or foraging strategy categories) and $\mathrm{B}=1 / \Sigma_{\mathrm{i}=1}^{\mathrm{k}} p_{\mathrm{i}}^{2}$, where $p_{i}$ is the observed frequency of resource category $i$. Frequencies for diet and foraging strategies were based on data from Wilman et al. (2014) which provides semi-qualitative estimates (in $10 \%$ intervals) of the percentage of each species diet represented by items in each of ten diet categories and seven types of foraging strategies. Frequencies for habitat were based on the proportion of each of the 14 biomes defined by Olson et al. (2001) represented within the neotropical distribution range of each bird species (the range defined above). Diet type, foraging strategy, and biome categories represent the possible resources ( $k$ in the equation above). Details on the collection and preparation of the intrinsic data are in Section 2 of Appendix 1.

Values for extrinsic drivers of risk were calculated over each species' distribution range (within the Neotropics) to estimate: mean night light, mean human population density, proportion of natural area, and mean human footprint (Table 1). Night light and human population density values were rescaled as suggested by the data source authors to values of radiance of $0-63$ and $0-10000$ people $/ \mathrm{m}^{2}$ respectively using the Raster Calculator tool (ESRI 2014) (Section 3.3.2 of Appendix 1). Means were calculated as arithmetic means of raster values using the Zonal Statistic Plugin in QGIS 2.2 (Quantum GIS Development Team 2017). The area of the distribution range within the Neotropics was also estimated for each species and included as a covariate in the analyses. Details on the collection and preparation of the extrinsic data are in Section 3 of Appendix 1.

Some predictors were $\log _{10}$ transformed to best meet the linear relationship assumption in our model and to reflect the expected non-linearities in some relationships (e.g., increased risk due to a $1 \mathrm{~g}$ increase in body size would be different for a small vs a large bird. Table 1). To facilitate comparison among predictors measured in different units and scales all were scaled (subtracting mean and dividing by the standard deviation) prior to analyses (Section 4 Appendix 1). To address possible collinearity issues we estimated correlations among variables using pairwise Spearman tests, "cor" function in R (R Development Core Team 2016) and 
evaluated the covariation among coefficient estimates across iterations after model fitting. We found strong correlations (Spearman $r>|0.80|$ Fig. A1.1) among some variables. Among those, as expected, the human footprint index was highly correlated with the other extrinsic factors (this index is, in fact, calculated combining data from some of these indicators like human population density and night light). Thus, we decided to consider the human footprint separately in the analyses. We maintained other correlated variables together in the analyses because we found no strong covariation among coefficients estimates across iterations.

Our dependent variable or response was extinction risk based on the IUCN Red List (IUCN 2017). Red List categories were converted into numerical values as follows: Least concern (LC): 1; Near threatened (NT): 2; Vulnerable (VU): 3; Endangered (EN): 4; Critically endangered (CR): 5. Converting ordinal status into a numerical variable is necessary for the modeling approach we used here and has been shown to be a robust approach in comparative studies (Yee and Juliano 2007, Matthews et al. 2011). Because our models included distribution range area as a predictor of risk, we excluded species listed as threatened based only on criterion B (small range size) to avoid circularity (Sodhi et al. 2008, Machado and Loyola 2013). After data were analyzed and the manuscript prepared the IUCN published an updated Red List assessment (IUCN 2017). This update only affected 20 neotropical bird species $(0.88 \%$ of the total) with both uplisting $(0.35 \%)$ and downlisting $(0.53 \%)$. Given this minimal change and to avoid time-consuming reanalyses we report results based on the 2017 assessment.

\section{Comparative Analysis}

We predicted the dependent variable Red List status for all neotropical birds as a function of the intrinsic and extrinsic predictors described above by fitting Bayesian Phylogenetic Generalized Least-Squares (PGLS) regression models implemented in Bayestraits 3.0 (Pagel et al. 2004). In these models, each species was represented by its Red List status and values for each predictor. For each species we used a single value, ignoring intraspecific variation (differences among individuals and populations of the same species), this assumption was necessary because estimates of variation are not available more most of the species studied for which often just a single value was available. Lack of data on intraspecific variation in comparative studies is common (Ives et al. 2007). Given our large sample of species expanding a wide range of variability in the predictors tested we consider ignoring intraspecific variation is unlikely to qualitatively affect results (because the considered interspecific variability is much larger than the within-species variation). We could have incorporated spatial variability within each species' distribution range for extrinsic predictors but we opted for an average to have similar descriptors of intrinsic and extrinsic factors and to avoid issues related to spatial autocorrelation (Mets et al. 2017).

Species data do not represent independent observations as assume by standard regression models because their characteristics and biogeography are influenced by their ancestor-descendant relationships. The approach we used (PGLS $\lambda$, sensu Revell 2010) enabled us to account for this non-independence modifying the variance-covariance matrix with a branch-scaling parameter $\lambda$.
This parameter was estimated in a Bayesian framework using a sample of 1500 phylogenetic trees representing the ancestordescendant relationships of all neotropical birds. The trees were obtained from BirdTree.org database (Jetz et al. 2012) using "Ericson All Species: a set of 10000 trees with 9993 OTUs each" (Appendix 1). Using a tree sample allowed us to incorporate uncertainty in the ancestor-descendant relationships. All regression models were run for $10 \times 10^{6}$ iterations, burning in the first 1100 iterations and estimating $\lambda$.

We fitted three separated regression models to explore the importance of 1) only intrinsic, 2) only extrinsic, and 3) both types of drivers. As mentioned above distribution range area was included as a predictor in all analyses. We assess variable importance based on the proportion (p) of the posterior distribution of the estimated coefficient parameter $(\beta)$ with signs opposite from that of the median value, with proportions $\mathrm{p}<0.1$ interpreted as evidence of supported effects.

\section{RESULTS}

Models including intrinsic and extrinsic factors revealed higher risk for species with larger body sizes, smaller maximum clutch sizes, that are ecologically specialized (more limited foraging strategies), and that occupied narrower ranges characterized by lower night light and lower human population densities (Fig. 1c). For models with intrinsic variables and human footprint as a general descriptor of extrinsic impacts (this predictor was analyzed separately due to its high correlation with others), higher risk was associated with higher human footprint values, larger body sizes, smaller maximum clutch sizes, and narrow ranges, with a less clear role of specialization (Fig. A1.2). The proportion of natural area in a species range was not a significant predictor in any of the tested models.

While we identified a total of 2485 endemic neotropical bird species, data for all variables were not available for all species (Fig. 2 ). The main model with all predictors reported above included 1248 species but to explore consistency of results with as many species as possible we fitted additional models for the 2268 species for which only extrinsic variables were available (testing only these factors), and the 1959 species with data on all predictors except maximum clutch size (the most limiting variable). These additional analyses show consistent results and are shown in Appendix 1 (Figs. A1.3-A1.6). The neotropical bird species considered in our analyses represented 70 taxonomic families and 24 orders (Fig. 2). While trait data were more limited for some orders, the analyzed species were an overall representative sample of all neotropical birds currently assessed by the IUCN (Fig A1.7). In most orders, $>50 \%$ of the species were classified as low risk (Least Concern) category. However, risk was higher in some groups (Accipitriformes, Galliformes, Phoenicopteriformes, and Psittaciformes) with relatively high numbers of Endangered and Critically Endangered species (Fig. 1; Table A1.1).

The influence and effects of intrinsic and extrinsic factors were supported in models that considered each type separately. Models focused only on intrinsic variables showed higher risk associated with larger body size, greater specialization (in this case represented by narrower habitat breadth), smaller maximum clutch size, and as expected narrower distribution ranges (Fig.1a). Analyses focused on extrinsic variables also showed higher risk 
Fig. 1. Model results showing the effects (posterior distribution of the regression slope, $\beta$ ) of different predictors in the response variable extinction risk (Red List status). Results represent three models fitting with data from 1248 species for: a) only intrinsic predictors, b) only extrinsic predictors, and c) both intrinsic and extrinsic predictors. Model fit described by estimated R2 is provided for each model. Small numbers between 0 and 1 within panels represent the support of each effect quantified by the proportion of estimates with signs equal to that of the median value. We considered $\mathrm{p}<0.1$ (distributions shown with a red fill) indicates strong support for an effect. * $\log 10$-transformed variables. †variables described as the arithmetic mean.

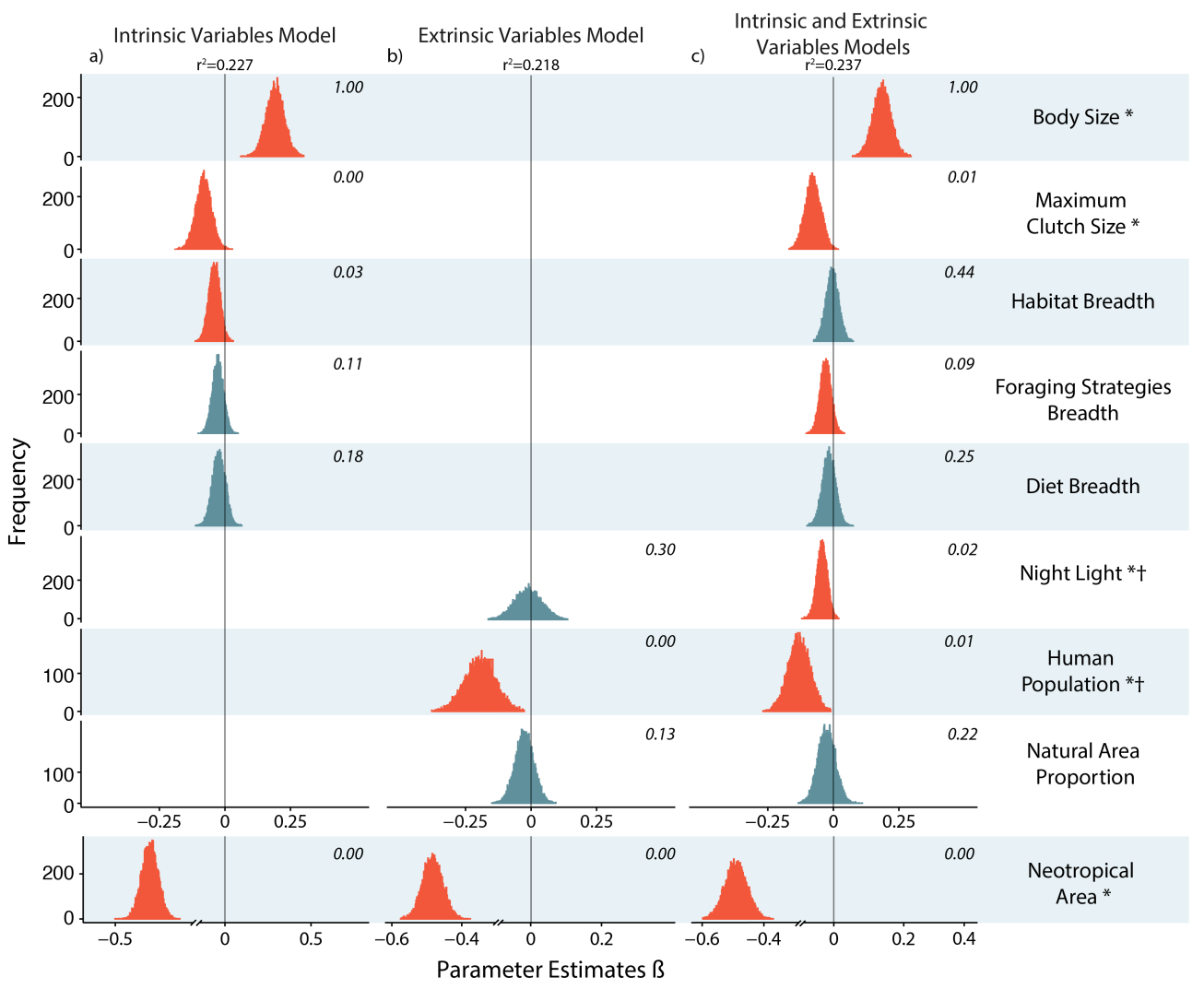

associated with less human impact described by lower human densities (Fig. 1b) and with a lower human footprint (Figs. A1.5A1.6). Results were generally consistent with the alternative models that considered fewer predictors to increase the sample size (representing more neotropical bird species), although these models identified as relevant different descriptors of ecological specialization (narrow diet breadth and more limited foraging strategies) and of human impact (lower night light levels. Figs. A1.3-A1.4).

\section{DISCUSSION}

Our results reveal effects of both intrinsic and extrinsic drivers in the extinction risk of neotropical birds. In general, risk of extinction was higher for bigger and more specialized species, with lower reproductive output, and that occupy smaller distribution ranges in areas with fewer human activities (lower night light levels and smaller human population densities). Species such as Daptrius ater and Vultur gryphus with their larger size and specialization have higher risk than smaller species such as Troglodytes solstitialis and Sporophila minuta. In addition, species with similar intrinsic traits such as Anthracothorax viridis and Turdus infuscatus which overlap more anthropized areas have lower risk than species such as Troglodytes monticola now found largely in natural environments. The effects of intrinsic and extrinsic were similar when tested together and independently, suggesting both factors are important and need to be considered together. However, we note the importance of the different variables that describe ecological specialization did change slightly, suggesting some possible covariation among predictors (see Fig. A1.8-A1.10). As in previous work (Bennett and Owens 1997, Wang et al. 2017), we found that extinction risk is not randomly distributed among bird taxa.

The association between body size and vulnerability to extinction has been found in previous studies (Bennett and Owens 1997, Lee and Jetz 2010, Wang et al. 2017), and here we show it affects neotropical birds too. This relationship may reflect different mechanisms. First, larger species are more susceptible to some threats, like direct exploitation (Owens and Bennett 2000, Chichorro et al. 2019), therefore body size could be a direct vulnerability factor. In addition, species with larger body sizes 
Fig. 2. Characterization of data availability and extinction risk categories for each avian taxonomic order included in the analyses. Circular bars represent the percentage of bird species with data available for each of the different intrinsic variables considered (left bars), and percentage of species in each IUCN Red List Categories (right bars). The central number over each bird silhouette is the total number of species recognized in that order. Orders with left bars covering most of the left semicircle represent groups with good data coverage (i.e., Pelecaniformes). Body Size and Habitat Breadth are not shown because data were available for all species. LC=Least Concern, NT = Near Threatened, VU= Vulnerable, EN=Endangered, CR=Critically Endangered.

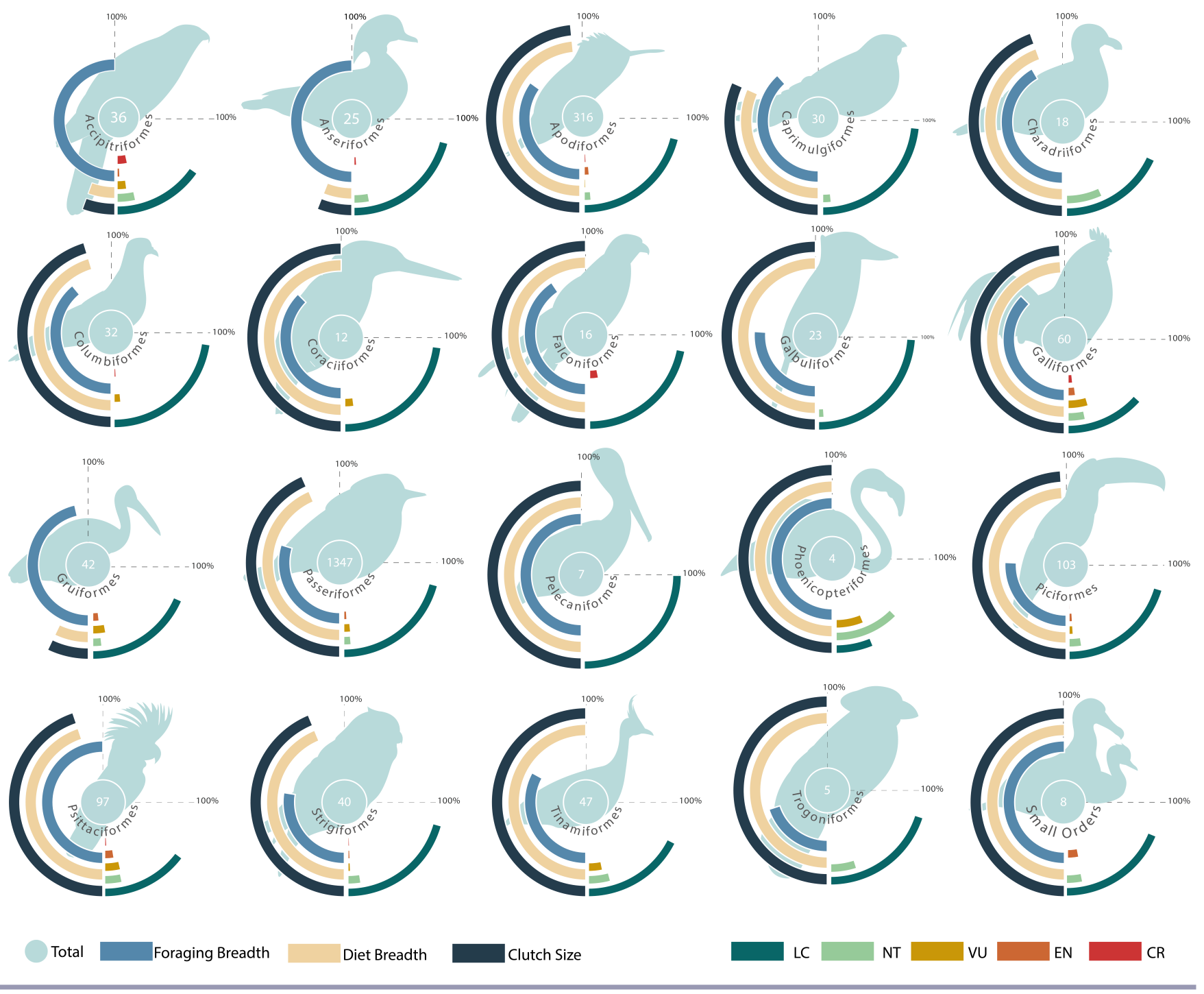

have slower reproductive rates (Gaston and Blackburn 1995), and thus, less capacity to compensate for the direct losses produced by anthropic activities which can increase their vulnerability to extinction (Owens and Bennett 2000, Quesnelle et al. 2014). Interestingly, in our analyses body size was a relevant predictor even when including a direct descriptor of reproductive rate, maximum clutch size. Reproductive rates in mammals are best defined using two axes: output (how many) and timing (how often) (Bielby et al. 2007). It is likely these two axes are also relevant for birds, and maximum clutch size could represent the output axis of reproductive speed. In that case, body size could have remained an important predictor in our models because it captured the effect of timing on reproductive rates (Lislevand et al. 2007).
Unfortunately, we could not directly test the role of reproductive timing because data were not available for many of the species analyzed here.

Similarly, previous studies have also suggested that more specialized species are less likely to be supported in humanized environments (Gaston and Blackburn 1997, Altaf et al. 2018, Garcia and Di Marco 2020). Although our analyses show a consistent negative effect of specialization in neotropical birds, interestingly, results for different datasets and variable combinations identified different descriptors of specialization as important. This highlights the importance of considering multiple descriptors when representing complex characteristics 
like niche breadth, and the value of testing results across datasets when information is limited. When data are missing, imputation approaches may be used to fill gaps (Johnson et al. 2020). However, trait data are often not missing at random (GonzálezSuárez et al. 2012) and imputation based on biased samples can lead to errors (Johnson et al. 2020). A solution, we implemented here, is to explore the available information by using different subsets in separate analyses that are then compared. In this way, one can maximize the use of existing trait data while also representing as many species as possible in the different steps of the analyses.

Our results also revealed extrinsic factors as predictors of extinction risk. We did not find a link between higher human impacts and higher extinction risk, but instead evidence for what we can call a refuge relationship. We hypothesize this may reflect a process by which the most vulnerable species already disappeared from impacted areas and now those that remain, do so as threatened in more natural regions. A similar relationship has been described with mammals in the Neotropics by Polaina et al. (2018) who found that threatened mammals were more abundant in areas with more forest cover and thus, less modified. Interestingly in our analyses, we found no clear association of risk with the proportion of natural areas overlapping a species range. These natural areas are generally considered as important for conservation and protection, it is possible these areas both offer protection to some species which are then able to remain unthreatened and act as refuges for those already impacted elsewhere and likely threatened by those impact and range loss, leading to a balance that in a macroecological analysis, such as our study, would appear as no effect or benefit.

Threatened birds concentrate on less modified environments, yet these potential refuges could be soon compromised given the predicted rapid development and urbanization of the Neotropics. This is a worrying prediction. On the other hand, humanized environments can offer advantages for adapted birds. For example, Zenaida auriculata, has been noted for its ability to adapt to agricultural areas even depending on them (Silva et al. 2018). Phalcoboenus chimango, is widely known in South America as an excellent model of adaptation and use of anthropized environments, through its natural history, it went from being a locally threatened species to a competitor with other cosmopolitan urban birds such as Passer domesticus (SotoSaravia et al. 2017). Advantages may also be associated with some specific factors, artificial night light influences reproductive physiology (Dominoni et al. 2013, 2020) and breeding timing (de Jong et al. 2015, Dominoni and Nelson 2018), which can increase reproductive output and thus, lead to reduced risk in species able to persist in modified habitats (Dominoni 2017). Similarly, areas with higher population densities could provide habitat and food resources for many species (Chace and Walsh 2006, Seress and Liker 2015, Prestes et al. 2018). Overall, it is likely some species will benefit from human activities, and future work on different groups and areas will be needed to better understand how urbanization will affect neotropical birds.

For macroecological studies, a major limitation is often data availability, especially for the most threatened species. For some Neotropical birds (e.g., Troglodytes monticola, Celeus obrieni, or Perija Thistletail), we only have the original description and sporadic observations. Not only data are often missing for many species, but the types of data that are available do not include all potentially relevant types of predictors. For example, behavioral data are often only available for a handful of species, and this limitation generally prevents their consideration from broad analyses such as ours, even though aspects such as nest habitat selection or social interactions are likely important (Reed 1999, Clavel et al. 2011, Ducatez et al. 2015, Case and Tarwater 2020, Lees et al. 2020). Similarly, as mentioned above limited availability of descriptors of reproductive timing preventing us from exploring the role of aspect of life-history speed. This issue is not limited to intrinsic predictors, for example, inconsistencies in the criteria used to delimit urban areas in different regions prevented us from considering level of urbanization in our study. Different countries define urban areas based on distinct criteria such as population density or the type and number of services available (Lattes 2001, U.N 2018). In less developed areas large human settlements with few services can occur in some regions, which means these differences in criteria can affect the classification. Similarly, inconsistencies in how socioeconomic development indicators are collected across the Neotropics make it difficult to test the role of these potentially important factors. Large-scale analyses such as ours often highlight the importance of increasing the availability of comprehensive and standardized data. Natural history studies describing species behavior and characteristics have become increasingly rare, yet this information is key to ensure conservation assessment and management are done as effectively as possible. Good, consistent descriptors of human pressure are also key. For some variables new, high-resolution remote sensing technology may offer an answer. For others, standardized approaches and good data sharing policies would be required to provide comparable information across large regions.

\section{CONCLUSIONS}

We found that risk of extinction in neotropical birds is associated with several intrinsic and extrinsic factors. Our study contributes to understanding extinction risk factors in the Neotropics in two important ways. First, it provides a generalized, broad assessment of risk for a wide region and taxonomic groups building on previous local and taxa-specific findings and updating a previous macroecological analysis completed 17 years ago that had not considered anthropogenic impacts (Gage et al. 2004). Second, our study offers a novel holistic view of risk for this area considering both intrinsic and extrinsic factors. These contributions can be useful for initial conservation management and prioritization. We found identified intrinsic factors similar to those reported by other regions and taxa, supporting a pattern of generalized vulnerability for larger, slowly reproducing, and ecologically specialized vertebrates that may be prioritized initially (or when other information is not available) for monitoring, management, and conservation actions. Our results also link risk to human activities, showing that threatened species are currently found in more natural refuges (less impacted, anthropized areas). Protecting these less impacted refuges should be a priority, as they host threatened species that could likely become extinct if humans continue to encroach on the natural habitats.

Responses to this article can be read online at: https://www.ace-eco.org/issues/responses.php/1948 


\section{Acknowledgments:}

This work is part of the PhD thesis of R.S-S., supported by the CONICYT Doctoral Fellowship 2016- 21161285. C.E.H. was supported by FONDECYT grant 1201506. This work is part of the Master's degree of C. G-C "Magister en Análisis Geográfico" of Facultad de Arquitectura Urbanismo y Geografía. Universidad de Concepción.

\section{LITERATURE CITED}

Altaf, M., A. Javid, A. M. Khan, M. S. H. Khan, M. Umair, and Z. Ali. 2018. Anthropogenic impact on the distribution of the birds in the tropical thorn forest, Punjab, Pakistan. Journal of Asia-Pacific Biodiversity 11:229-236. https://doi.org/10.1016/j. japb.2018.03.001

Aubé, M., J. Roby, and M. Kocifaj. 2013. Evaluating potential spectral impacts of various artificial lights on melatonin suppression, photosynthesis, and star visibility. PLoS ONE 8: e67798. https://doi.org/10.1371/journal.pone.0067798

Baiser, B., J. D. Olden, S. Record, J. L. Lockwood, and M. L. McKinney. 2012. Pattern and process of biotic homogenization in the New Pangaea. Proceedings of the Royal Society B: Biological Sciences 279:4772-4777. https://doi.org/10.1098/ rspb.2012.1651

Barnosky, A. D., E. A. Hadly, J. Bascompte, E. L. Berlow, J. H. Brown, M. Fortelius, W. M. Getz, J. Harte, A. Hastings, P. A. Marquet, N. D. Martinez, A. Mooers, P. Roopnarine, G. Vermeij, J. W. Williams, R. Gillespie, J. Kitzes, C. Marshall, N. Matzke, D. P. Mindell, E. Revilla, and A. B. Smith. 2012. Approaching a state shift in Earth's biosphere. Nature 486:52-58. https://doi. org/10.1038/nature11018

Bennett, P. M., and I. P. F. Owens. 1997. Variation in extinction risk among birds: chance or evolutionary predisposition? Proceedings of the Royal Society B: Biological Sciences 264:401-408. https://doi.org//10.1098/rspb.1997.0057

Bielby, J., G. M. Mace, O. R. P. Bininda-Emonds, M. Cardillo, J. L. Gittleman, K. E. Jones, C. D. L. Orme, and A. Purvis. 2007. The fast-slow continuum in mammalian life history: an empirical reevaluation. The American Naturalist 169:748-757. https://doi. org/10.1086/516847

Billerman, S. M., B. K. Keeney, P. G. Rodewal, and T. S. Schulenberg. 2020. Birds of the World. Cornell Laboratory of Ornithology. Ithaca, NY, USA. https://birdsoftheworld.org/bow/ home

BirdLife International. 2020. IUCN Red List for birds: distribution maps. http://www.birdlife.org/

Brown, J. H., and B. A. Maurer. 1989. Macroecology: the division of food and space among species on continents. Science 243:1145-1150. https://doi.org/10.1126/science.243.4895.1145

Cabrera-Cruz, S. A., J. A. Smolinsky, and J. J. Buler. 2018. Light pollution is greatest within migration passage areas for nocturnally-migrating birds around the world. Scientific Reports 8:3261. https://doi.org/10.1038/s41598-018-21577-6
Cabrera-Cruz, S. A., J. A. Smolinsky, K. P. McCarthy, and J. J. Buler. 2019. Urban areas affect flight altitudes of nocturnally migrating birds. Journal of Animal Ecology 88:1873-1887. https:// doi.org/10.1111/1365-2656.13075

Case, S. B., and C. E. Tarwater. 2020. Functional traits of avian frugivores have shifted following species extinction and introduction in the Hawaiian Islands. Functional Ecology 34:2467-2476. https://doi.org/10.1111/1365-2435.13670

Chace, J. F., and J. J. Walsh. 2006. Urban effects on native avifauna: a review. Landscape and Urban Planning 74:46-69. https://doi.org/10.1016/j.landurbplan.2004.08.007

Chepesiuk, R. 2009. Missing the dark: health effects of light pollution. Environmental Health Perspectives 117:A20-A27. https://doi.org/10.1289/ehp.117-a20

Chichorro, F., A. Juslén, and P. Cardoso. 2019. A review of the relation between species traits and extinction risk. Biological Conservation 237:220-229. https://doi.org/10.1016/j.biocon.2019.07.001

Clavel, J., R. Julliard, and V. Devictor. 2011. Worldwide decline of specialist species: toward a global functional homogenization? Frontiers in Ecology and the Environment 9:222-228. https://doi. org/10.1890/080216

Colles, A., L. H. Liow, and A. Prinzing. 2009. Are specialists at risk under environmental change? Neoecological, paleoecological and phylogenetic approaches. Ecology Letters 12:849-863. https:// doi.org/10.1111/j.1461-0248.2009.01336.x

Correll, M. D., W. A. Wiest, B. J. Olsen, W. G. Shriver, C. S. Elphick, and T. P. Hodgman. 2016. Habitat specialization explains avian persistence in tidal marshes. Ecosphere 7:e01506. https://doi.org/10.1002/ecs2.1506

Davidson, A. D., A. G. Boyer, H. Kim, S. Pompa-Mansilla, M. J. Hamilton, D. P. Costa, G. Ceballos, and J. H. Brown. 2012. Drivers and hotspots of extinction risk in marine mammals. Proceedings of the National Academy of Sciences 109:3395-3400. https://doi.org/10.1073/pnas.1121469109

Davies, T. W., J. Bennie, R. Inger, and K. J. Gaston. 2013. Artificial light alters natural regimes of night-time sky brightness. Scientific Reports 3:1722. https://doi.org/10.1038/srep01722

Davies, W. I. L., M. Turton, S. N. Peirson, B. K. Follett, S. Halford, J. M. Garcia-Fernandez, P. J. Sharp, M. W. Hankins, and R. G. Foster. 2012. Vertebrate ancient opsin photopigment spectra and the avian photoperiodic response. Biology Letters 8:291-294. https://doi.org/10.1098/rsbl.2011.0864

Devenish, C., E. N. Cortez, G. Buchanan, G. R. Smith, and S. J. Marsden. 2020. Estimating ecological metrics for holistic conservation management in a biodiverse but information-poor tropical region. Conservation Science and Practice 2:e153. https:// doi.org/10.1111/csp2.153

Dominoni, D. M. 2017. Ecological effects of light pollution: how can we improve our understanding using light loggers on individual animals? Pages 251-270 in Ecology and Conservation of Birds in Urban Environments. Springer International Publishing, Cham. https://doi.org/10.1007/978-3-319-43314-1_13 
Dominoni, D. M., J. K. Jensen, M. de Jong, M. E. Visser, and K. Spoelstra. 2020. Artificial light at night, in interaction with spring temperature, modulates timing of reproduction in a passerine bird. Ecological Applications 30:e02062. https://doi.org/10.1002/ eap. 2062

Dominoni, D. M., and R. J. Nelson. 2018. Artificial light at night as an environmental pollutant: an integrative approach across taxa, biological functions, and scientific disciplines. Journal of Experimental Zoology 329:387-393. https://doi.org/10.1002/ jez.2241

Dominoni, D., M. Quetting, and J. Partecke. 2013. Artificial light at night advances avian reproductive physiology. Proceedings of the Royal Society B: Biological Sciences 280:20123017-20123017. https://doi.org/10.1098/rspb.2012.3017

Ducatez, S., J. Clavel, and L. Lefebvre. 2015. Ecological generalism and behavioural innovation in birds: technical intelligence or the simple incorporation of new foods? Journal of Animal Ecology 84:79-89. https://doi.org/10.1111/1365-2656.12255

Durán, A. P., J. M. H. Green, C. D. West, P. Visconti, N. D. Burgess, M. Virah-Sawmy, and A. Balmford. 2020. A practical approach to measuring the biodiversity impacts of land conversion. Methods in Ecology and Evolution 11:910-921. https://doi.org/10.1111/2041-210X.13427

ESRI. 2014. Environmental Systems Research Institute (ESRI). Redlands, CA, USA.

Ferretti, V. 2019. Understanding variation in extra-pair paternity in birds: a focus on Neotropical birds. Pages 21-40 in J. C. Reboreda, V. D. Fiorini, and D. T. Tuero, editors. Behavioral Ecology of Neotropical Birds. Springer International Publishing, Cham. https://doi.org/10.1007/978-3-030-14280-3_2

Fisher, D. O., I. P. F. Owens, and C. N. Johnson. 2001. The ecological basis of life history variation in marsupials. Ecology 82:3531-3540. https://doi.org/10.1890/0012-9658(2001)082[3531: TEBOLH]2.0.CO;2

Forester, D. J., and G. E. Machlist. 1996. Modeling human factors that affect the loss of biodiversity. Conservation Biology 10:1253-1263. https://doi.org/10.1046/j.1523-1739.1996.10041253. $\mathrm{x}$

Gage, G. S., M. de L. Brooke, M. R. E. Symonds, and D. Wege. 2004. Ecological correlates of the threat of extinction in Neotropical bird species. Animal Conservation 7:161-168. https:// doi.org/10.1017/S1367943004001246

Garcia, R, J. C., and M. Di Marco. 2020. Drivers and trends in the extinction risk of New Zealand's endemic birds. Biological Conservation 249:108730. https://doi.org/10.1016/j.biocon.2020.108730

Gaston, K., and T. Blackburn. 2000. Pattern and Process in Macroecology. Blackwell Science Ltd, Malden, MA, USA. https://doi.org/10.1002/9780470999592

Gaston, K. J., and T. M. Blackburn. 1995. Birds, body size and the threat of extinction. Philosophical Transactions of the Royal Society B: Biological Sciences 347:205-212. https://doi. org/10.1098/rstb. 1995.0022
Gaston, K. J., and T. M. Blackburn. 1997. Evolutionary age and risk of extinction in the global avifauna. Evolutionary Ecology 11:557-565. https://doi.org/10.1007/s10682-997-1511-4

Gaston, K. J., M. E. Visser, and F. Hölker. 2015. The biological impacts of artificial light at night: the research challenge. Philosophical Transactions of the Royal Society B: Biological Sciences 370:20140133. https://doi.org/10.1098/rstb.2014.0133

Geiser, F., and C. Turbill. 2009. Hibernation and daily torpor minimize mammalian extinctions. Naturwissenschaften 96:1235-1240. https://doi.org/10.1007/s00114-009-0583-0

Gonzalez-Suarez, M., A. Gomez, and E. Revilla. 2013. Which intrinsic traits predict vulnerability to extinction depends on the actual threatening processes. Ecosphere 4:1-16.

González-Suárez, M., A. Gómez, and E. Revilla. 2013. Which intrinsic traits predict vulnerability to extinction depends on the actual threatening processes. Ecosphere 4:1-16. https://doi. org/10.1890/ES12-00380.1

González-Suárez, M., P. M. Lucas, and E. Revilla. 2012. Biases in comparative analyses of extinction risk: mind the gap. Journal of Animal Ecology 81:1211-1222. https://doi.org/10.1111/ j.1365-2656.2012.01999.x

González-Suárez, M., and E. Revilla. 2013. Variability in lifehistory and ecological traits is a buffer against extinction in mammals. Ecology Letters 16:242-251. https://doi.org/10.1111/ ele. 12035

Green, J. M. H., S. A. Croft, A. P. Durán, A. P. Balmford, N. D. Burgess, S. Fick, T. A. Gardner, J. Godar, C. Suavet, M. VirahSawmy, L. E. Young, and C. D. West. 2019. Linking global drivers of agricultural trade to on-the-ground impacts on biodiversity. Proceedings of the National Academy of Sciences 116:23202-23208. https://doi.org/10.1073/pnas.1905618116

Harrison, S., and R. Noss. 2017. Endemism hotspots are linked to stable climatic refugia. Annals of Botany 119:207-214. https:// doi.org/10.1093/aob/mcw248

Horton, K. G., C. Nilsson, B. M. Van Doren, F. A. La Sorte, A. M. Dokter, and A. Farnsworth. 2019. Bright lights in the big cities: migratory birds' exposure to artificial light. Frontiers in Ecology and the Environment 17:209-214. https://doi.org/10.1002/ fee. 2029

Isaksson, C. 2018. Impact of Urbanization on Birds. Pages 235-257 in D. T. Tietze, editor. Bird Species. Springer International Publishing, Cham. https://doi.org/10.1007/978-3-319-91689-7_13

\section{IUCN. 2017. The IUCN Red List of Threatened Species.}

IUCN. 2020. The IUCN Red List of Threatened Species. Version 2020-3.

Ives, A. R., P. E. Midford, and T. Garland Jr. 2007. Within-species variation and measurement error in phylogenetic comparative methods. Systematic Biology 56:252-270. https://doi. org/10.1080/10635150701313830

Jetz, W., G. H. Thomas, J. B. Joy, K. Hartmann, and A. O. Mooers. 2012. The global diversity of birds in space and time. Nature 491:444-448. https://doi.org/10.1038/nature11631 
Avian Conservation and Ecology 16(2): 18 http://www.ace-eco.org/vol16/iss2/art18/

Johnson, T. F., N. J. B. Isaac, A. Paviolo, and M. González-Suárez. 2020. Handling missing values in trait data. Global Ecology and Biogeography 30:51-62. https://doi.org/10.1111/geb.13185

de Jong, M., J. Q. Ouyang, A. Da Silva, R. H. A. van Grunsven, B. Kempenaers, M. E. Visser, and K. Spoelstra. 2015. Effects of nocturnal illumination on life-history decisions and fitness in two wild songbird species. Philosophical Transactions of the Royal Society B: Biological Sciences 370:20140128-20140128. https:// doi.org/10.1098/rstb.2014.0128

Kronfeld-Schor, N., D. Dominoni, H. de la Iglesia, O. Levy, E. D. Herzog, T. Dayan, and C. Helfrich-Forster. 2013. Chronobiology by moonlight. Proceedings of the Royal Society B: Biological Sciences 280:20123088-20123088. https://doi. org/10.1098/rspb.2012.3088

Lattes, A. 2001. Población urbana y urbanización en América Latina. Page 204 in F. Carrión, editor. La ciudad construida. Urbanismo en América Latina. FLACSO, Ecuador, Quito.

Lee, T. M., and W. Jetz. 2010. Unravelling the structure of species extinction risk for predictive conservation science. Proceedings of the Royal Society B: Biological Sciences. https://doi.org/10.1098/ rspb.2010.1877

Lees, A. C., C. Devenish, J. I. Areta, C. B. de Araújo, C. Keller, B. Phalan, and L. F. Silveira. 2021. Assessing the extinction probability of the Purple-winged Ground Dove, an enigmatic bamboo specialist. Frontiers in Ecology and Evolution 9. https:// doi.org/10.3389/fevo.2021.624959

Lees, A. C., and C. A. Peres. 2008. Avian life-history determinants of local extinction risk in a hyper-fragmented neotropical forest landscape. Animal Conservation 11:128-137. https://doi. org/10.1111/j.1469-1795.2008.00162.X

Lees, A. C., K. V. Rosenberg, V. Ruiz-Gutierrez, S. Marsden, T. S. Schulenberg, and A. D. Rodewald. 2020. A roadmap to identifying and filling shortfalls in Neotropical ornithology. The Auk 137. https://doi.org/10.1093/auk/ukaa048

Levins, R. 1968. Evolution in Changing Environments: Some Theoretical Explorations, 1st edition. Princeton University Press.

Lislevand, T., J. Figuerola, and T. Székely. 2007. Avian body sizes in relation to fecundity, mating system, display Behavior, and resource sharing. Ecology 88:1605-1605. https://doi.org/10.1890/06-2054

Machado, N., and R. D. Loyola. 2013. A comprehensive quantitative assessment of bird extinction risk in Brazil. PLoS ONE 8. https://doi.org/10.1371/journal.pone.0072283

Matthews, L. J., C. Arnold, Z. Machanda, and C. L. Nunn. 2011. Primate extinction risk and historical patterns of speciation and extinction in relation to body mass. Proceedings of the Royal Society B: Biological Sciences 278:1256-1263. https://doi. org/10.1098/rspb.2010.1489

McKinney, M. L. 2006. Urbanization as a major cause of biotic homogenization. Biological Conservation 127:247-260. https:// doi.org/10.1016/j.biocon.2005.09.005

Mets, K. D., D. Armenteras, and L. M. Dávalos. 2017. Spatial autocorrelation reduces model precision and predictive power in deforestation analyses. Ecosphere 8:e01824. https://doi. org/10.1002/ecs 2.1824

Olah, G., S. H. M. Butchart, A. Symes, I. M. Guzmán, R. Cunningham, D. J. Brightsmith, and R. Heinsohn. 2016. Ecological and socio-economic factors affecting extinction risk in parrots. Biodiversity and Conservation 25:205-223. https://doi. org/10.1007/s10531-015-1036-Z

Olson, D. M., E. Dinerstein, E. D. Wikramanayake, N. D. Burgess, G. V. N. Powell, E. C. Underwood, J. A. D'amico, I. Itoua, H. E. Strand, J. C. Morrison, C. J. Loucks, T. F. Allnutt, T. H. Ricketts, Y. Kura, J. F. Lamoreux, W. W. Wettengel, P. Hedao, and K. R. Kassem. 2001. Terrestrial ecoregions of the world: a new map of Life on Earth. BioScience 51:933-938. https://doi.org/10.1641/0006-3568 (2001)051[0933:TEOTWA]2.0.CO;2

Orme, C. D. L., R. G. Davies, M. Burgess, F. Eigenbrod, N. Pickup, V. A. Olson, A. J. Webster, T.-S. Ding, P. C. Rasmussen, R. S. Ridgely, A. J. Stattersfield, P. M. Bennett, T. M. Blackburn, K. J. Gaston, and I. P. F. Owens. 2005. Global hotspots of species richness are not congruent with endemism or threat. Nature 436:1016-1019. https://doi.org/10.1038/nature03850

Owens, I. P. F., and P. M. Bennett. 2000. Ecological basis of extinction risk in birds: Habitat loss versus human persecution and introduced predators. Proceedings of the National Academy of Sciences 97:12144-12148. https://doi.org/10.1073/pnas.200223397

Pagel, M., A. Meade, and D. Barker. 2004. Bayesian estimation of ancestral character states on phylogenies. Systematic Biology 53:673-684. https://doi.org/10.1080/10635150490522232

Pichorim, M., D. Valdenor de Oliveira, T. M. de Oliveira Júnior, T. P. F. Câmara, and É. P. Galvão do Nascimento. 2016. Pristine semi-arid areas in northeastern Brazil remain mainly on slopes of mountain ranges: a case study based on bird community of Serra de Santana. Tropical Zoology 29:189-204. https://doi. org/10.1080/03946975.2016.1235426

Prestes, T. V., L. T. Manica, and A. C. de Guaraldo. 2018. Behavioral responses of urban birds to human disturbance in urban parks at Curitiba, Paraná (Brazil). Revista Brasileira de Ornitologia 26:77-81. https://doi.org/10.1007/BF03544418

Prieto-Torres, D. A., L. A. Sánchez-González, M. F. OrtizRamírez, J. E. Ramírez-Albores, E. A. García-Trejo, and A. G. Navarro-Sigüenza. 2021. Climate warming affects spatiotemporal biodiversity patterns of a highly vulnerable Neotropical avifauna. Climatic Change 165:57. https://doi.org/10.1007/ s10584-021-03091-3

Purvis, A., M. Cardillo, R. Grenyer, and B. Collen. 2005. Correlates of extinction risk: phylogeny, biology, threat and scale. Pages 295-316 in A. Purvis, J. L. Gittleman, and T. Brooks, editors. Conservation biology 8: phylogeny and conservation. The Zoological Society of London, New York, NY. https://doi. org/10.1017/CBO9780511614927.013

Quantum GIS Development Team. 2017. Quantum GIS Geographic Information System. Open Source Geospatial Foundation Project.

Quesnelle, P. E., K. E. Lindsay, and L. Fahrig. 2014. Low reproductive rate predicts species sensitivity to habitat loss: A 
Avian Conservation and Ecology 16(2): 18

meta-analysis of wetland vertebrates. PLOS ONE 9:e90926. https://doi.org/10.1371/journal.pone.0090926

R Development Core Team. 2016. R: A Language and Environment for Statistical Computing. R Foundation for Statistical Computing Vienna Austria 0:\{ISBN\} 3-900051-07-0.

Reed, J. M. 1999. The Role of Behavior in Recent Avian Extinctions and Endangerments. Conservation Biology 13:232-241. https://doi.org/10.1046/j.1523-1739.1999.013002232. $\mathrm{x}$

Ribeiro, M. C., J. P. Metzger, A. C. Martensen, F. J. Ponzoni, and M. M. Hirota. 2009. The Brazilian Atlantic Forest: How much is left, and how is the remaining forest distributed? Implications for conservation. Biological Conservation 142:1141-1153. https:// doi.org/10.1016/j.biocon.2009.02.021

Rull, V., and T. Vegas-Vilarrúbia. 2017. Potential responses of vascular plants from the pristine "Lost World" of the Neotropical Guayana Highlands to global warming: review and new perspectives. Frontiers in Plant Science 8. https://doi.org/10.3389/ fpls.2017.00081

Sanderson, E., M. Jaiteh, M. Levy, K. Redford, A. Wannebo, and G. Woolmer. 2002. The human footprint and the last of the wild. BioScience 52:891. https://doi.org/10.1641/0006-3568(2002)052 [0891:THFATL]2.0.CO;2

Seress, G., and A. Liker. 2015. Habitat urbanization and its effects on birds. Acta Zoologica Academiae Scientiarum Hungaricae 61:373-408. https://doi.org/10.17109/AZH.61.4.373.2015

Silva, G. G., D. L. Guadagnin, G. G. Silva, and D. L. Guadagnin. 2018. Effect of land use in seasonal abundance of Eared Dove (Zenaida auriculata) in Southwestern Brazil. Brazilian Journal of Biology 78:18-24. https://doi.org/10.1590/1519-6984.21115

Sodhi, N. S., D. Bickford, A. C. Diesmos, T. M. Lee, L. P. Koh, B. W. Brook, C. H. Sekercioglu, and C. J. A. Bradshaw. 2008. Measuring the meltdown: drivers of global amphibian extinction and decline. PLoS ONE 3:1-8. https://doi.org/10.1371/journal. pone. 0001636

Sodhi, N. S., B. W. Brook, and C. J. A. Bradshaw. 2009. Chapter V.1: Causes and consequences of species extinctions. Pages 514-520 in S. A. Levin, S. R. Carpenter, C. H. Godfray, A. P. Kinzig, M. Loreau, J. B. Losos, B. Walker, and D. Wilcove, editors. Princeton Guide to Ecology.

Soto-Saravia, R., V. H. Ruiz, E. Vega-Roman, M. Marchant, and A. Benítez-Mora. 2017. A reassessment on the state of knowledge of Chilean Falconidae in the last hundred years. ZooKeys 642:131-148. https://doi.org/10.3897/zookeys.642.9877

Stouffer, P. C., R. O. Bierregaard, C. Strong, and T. E. Lovejoy. 2006. Long-term landscape change and bird abundance in
Amazonian rainforest fragments. Conservation Biology 20:1212-1223. https://doi.org/10.1111/j.1523-1739.2006.00427.x

Tabarelli, M., M. J. C. Da Silva, and C. Gascon. 2004. Forest fragmentation, synergisms and the impoverishment of neotropical forests. Biodiversity and Conservation 13:1419-1425. https://doi.org/10.1023/B:BIOC.0000019398.36045.1b

U.N. 2018. World Urbanization Prospects: The 2018 Revision, Online Edition. https://esa.un.org/unpd/wup/.

Wang, Y., X. Si, P. M. Bennett, C. Chen, D. Zeng, Y. Zhao, Y. Wu, and P. Ding. 2017. Ecological correlates of extinction risk in Chinese birds. Ecography:782-794. https://doi.org/10.1111/ ecog.03158

Weinzettel, J., D. Vačkář, and H. Medková. 2018. Human footprint in biodiversity hotspots. Frontiers in Ecology and the Environment 16:447-452. https://doi.org/10.1002/fee.1825

Wilman, H., J. Belmaker, J. Simpson, C. de la Rosa, M. M. Rivadeneira, and W. Jetz. 2014. EltonTraits 1.0: Species-level foraging attributes of the world's birds and mammals. Ecology 95:2027-2027. https://doi.org/10.1890/13-1917.1

Yee, D. A., and S. A. Juliano. 2007. Abundance matters: A field experiment testing the more individuals hypothesis for richnessproductivity relationships. Oecologia 153:153-162. https://doi. org/10.1007/s00442-007-0707-1
Editor-in-Chief: Keith A.Hobson Subject Editor: André A.Dhondt
Sponsored by the Society of Canadian Ornithologists and Birds Canada

Parrainée par la Société des ornithologistes du Canada et Oiseaux Canada

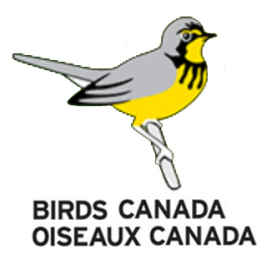




\section{SUPPLEMENTARY MATERIAL}

\section{DATA DISTRIBUTION COLLECTION PROTOCOL}

1.1. Data corresponding to 11120 bird species was downloaded from Birdlife International (BirdLife International 2020).

1.2. To reduce the process overhead, 4185 listed species from The Cornell Lab of Ornithology was selected, (from now called list (A)) and assigned a unique number (any) as identifier for the next step.

1.3. A "Joint function" between the list $(A)$ and bird species from Birdlife was made in ArcGis 10.1 (ESRI 2014). The resulting "Joint function" match the scientific name from BirdLife List and $(A)$ list, adding identifier number in a new field in the attribute table. Then only those with the identifier number was selected and exported.

1.4. Once exported, every shape was projected in to Cylindrical Equal Area, to avoid miscalculation in distribution area.

1.5. Distributions maps contains Origin, Presence and Seasonal information categories with five codes for each specie

1.5.1. A "Merge Function" on Origin category was made, adding only Native and Vagrant codes.

1.5.2. A "Merge Function" on Presence category was made, adding only Extant and Probably Extant codes.

1.5.3. A "Merge Function" on Seasonal category was made, adding Resident, Breeding Season, Non-breeding Season and Passage codes.

1.5.4. Note: Probably Extant code is no longer in use for reasons of ambiguity (BirdLife International 2020) and for those species that possess it was not considered.

1.6. The Neotropical Realm according to Olson (Olson et al. 2001) was downloaded and projected to Cylindrical Equal Area.

1.7. A "Clip function" between species shape and Neotropical Realm was made.

1.8. The differences between Total Area and Clip Area was obtained to establish the Neotropical Area and Non-Neotropical Area percentages.

1.9. Only those species with more than $80 \%$ of Neotropical Area was chosen.

\section{INTRINSIC DATA COLLECTION PROTOCOL}

2.1. With 2485 species defined previously, data for Body Size, Maximum Clutch Size, Diet Breadth, Habitat Breadth and Foraging Strategies Breadth was searched.

2.2. Body Size data was extracted one by one from the Birds of the World (HBW) series (Billerman et al. 2020), previous annual subscription.

2.3. Maximum Clutch Size was extracted the same as the previous point.

2.4. Diet and Foraging Strategies was extracted from EltonTraits 1.0 database (Wilman et al. 2014). This dataset provides semi-qualitative estimates (in 10\% intervals) of the percentage of each species diet represented by items in each of 10 diet categories (DietInv, Diet-Vend, Diet-Vect, Diet-Vfish, Diet-Vunk, Diet-Scav, Diet-Fruit, Diet-Nect, Diet-Seed, Diet-Plant), of the prevalence of each of several types of foraging strategies (ForStratwatbelowsurf, ForStrat-wataroundsurf, ForStrat-ground, ForStrat-understory, ForStratmidhigh, ForStrat-canopy, ForStrat-aerial). These percentages were used for $p_{\mathrm{i}}$ in equation 1 below. Specific details on how qualitative and quantitative data from the published 
literature were used to generate the species-level estimates in EltonTraits 1.0 are available in the metadata files of that publication (Wilman et al. 2014) available in

https://figshare.com/collections/EltonTraits 10 Species-

level foraging attributes of the world $s$ birds and mammals/3306933

2.5. Habitat Breath The habitat was extracted by calculating the percentage of overlap of each of the 14 biomes defined by Olson et al (2001), Tropical \& Subtropical Moist Broadleaf Forest, Tropical \& Subtropical Dry Broadleaf Forests, Tropical \& Subtropical Coniferous Forests, Temperate Broadleaf \& Mixed Forests, Temperate Conifer Forests, Boreal Forests / Taiga, Tropical \& Subtropical Grasslands, Savannas \& Shrublands, Temperate Grasslands, Savannas \& Shrublands, Flooded Grasslands \& Savannas, Montane Grasslands \& Shrublands, Tundra, Mediterranean Forests, Woodlands \& Scrub and Deserts \& Xeric Shrublands, Mangroves, with the range of distribution of each species.

2.5.1. Levin's index (Levins 1968) for each variable was calculated as follows:

$$
B=\frac{1}{\sum_{i=1}^{k} p_{i}^{2}} \quad \text { Eq. } 1
$$

Where $k$ is the number of resources (Food, Habitat and Foraging Strategies categories) and $p$ is the fraction of item in the categories that are resources categories.

2.5.2. Levin's standardized index for each variable was calculated as follows:

$$
B^{\prime}=\frac{B-1}{k-1}
$$

Eq. 2

2.5.3. Diet Breadth, Habitat Breadth and Foraging Strategies Breadth variables was incorporated to the main database using Merge function from package "reshape2" (Wickham 2007) in R (R Development Core Team 2016).

\section{EXTRINSIC DATA COLLECTION PROTOCOL}

3.1. Using the neotropical bird distribution shape defined in 1.9.

3.2. Night Light raster file was downloaded from https://ngdc.noaa.gov/eog/data/web data/v4composites/F182013.v4.tar (NOAA 2017).

3.2.1. The raster file was rescalated to the defined the author's values (0-63).

3.2.2. This procedure is strictly necessary, because the downloaded raster become like image file, with values of 8 bits (0-255). The rescaleted procedure was made using the Raster Calculator tool in ArcGis 10.1 as follows:

$$
\text { Rescalado }\left[\frac{\left(\gamma-\alpha_{\min }\right) *\left(\beta_{\max }-\beta_{\min }\right)}{\left(\alpha_{\max }-\alpha_{\min }\right)}\right]+\beta_{\min }
$$

Eq. 3 
Where $\gamma$ is the raster file selected in Raster Calculator tool, $\alpha_{\min }$ is the minimum value from grid, $\alpha_{\max }$ the maximum value from grid, $\beta_{\min }$ the minimum scale value and $\beta_{\max }$ the maximum scale value. Scale value from 0 to 63 . Grid value from 0 to 255 (8 bits).

3.2.3. Human Population Density raster file was downloaded from https://neo.sci.gsfc.nasa.gov/view.php?datasetld=SEDAC POP

3.2.3.1. Same prosedure descried in 3.2.1 and 3.2.2 was made. Sacale value from 0 to 10000.

3.2.4. Human Footprint raster file was donwloaded from http://sedac.ciesin.columbia.edu/data/set/wildareas-v2-human-footprintgeographic/data-download

3.2.5. Rescalated procedure not necessary.

3.3. All raster files were projected to Cylindrical Equal Area projection.

3.4. To obtain the Arithmetic Mean from the raster file from each specie distribution area, a Zonal Statistic Plugin was used, through QGIS 2.2 (Quantum GIS Development Team 2017).

3.4.1. As a raster layer Night Light, Human Population and Human Footprint was used, while as Polygon layer containing zones the bird distribution area was used.

3.5. Anthromes data (Ellis and Ramankutty 2008) was downloaded from http://ecotope.org/files/anthromes/anthromes v1.zip and projected to Cylindrical Equal Area.

3.5.1. A "Clip function" between species shape and Anthromes file was made.

3.5.2. A "Merge Function" on Anthromes for each specie was made and the final area calculated.

3.5.3. Natural Area Variable, is the sum of Wild Forest, Spare Tree and Barren areas.

3.5.4. Natural Area Proportion is the quotient between Natural Area (3.5.3) and Neotropical Area (1.9).

3.5.5. All previous data was added to main database using Merge function from package "reshape2" (Wickham 2007) in R (R Development Core Team 2016).

\section{FINAL TRANSFORMATION}

4.1. The variables transformed to $\log _{10}$ were those with biased distributions.

4.1.1. $\log _{10}$ (Body Size)

4.1.2. $\quad \log _{10}$ (Maximum Clutch Size)

4.1.3. $\log _{10}$ (Neotropical Area)

4.1.4. $\log _{10}$ (Night Light+1) (avoid Indeterminate log (0))

4.1.5. $\quad \log _{10}$ (Human Population+1) (avoid Indeterminate log (0))

4.1.6. $\quad \log _{10}$ (Human Footprint+1) (avoid Indeterminate log (0))

4.2. All data were escalated through "scale" function on R (R Development Core Team 2016).

4.2.1. "scale" function, calculate the mean and standard deviation of the entire vector, then "scale" each element by those values by subtracting the mean and dividing by the standard deviation. 
Table A1. Number of species and percentage of threatened (VU-EN-CR) for each family and order.

\begin{tabular}{|c|c|c|c|}
\hline Order & Family & Species & Threatened\% \\
\hline Rheiformes & Rheidae & 2 & 0.00 \\
\hline Tinamiformes & Tinamidae & 47 & 12.77 \\
\hline Anseriformes & Anatidae & 22 & 4.55 \\
\hline Anseriformes & Anhimidae & 3 & 0.00 \\
\hline \multirow[t]{3}{*}{ Galliformes } & Cracidae & 38 & 42.11 \\
\hline & Odontophoridae & 21 & 19.05 \\
\hline & Phasianidae & 1 & 0.00 \\
\hline Podicipediformes & Podicipedidae & 2 & 50.00 \\
\hline Phoenicopteriformes & Phoenicopteridae & 4 & 25.00 \\
\hline Ciconiiformes & Burhinidae & 2 & 0.00 \\
\hline \multirow[t]{2}{*}{ Pelecaniformes } & Ardeidae & 6 & 0.00 \\
\hline & Threskiornithidae & 1 & 0.00 \\
\hline \multirow[t]{2}{*}{ Accipitriformes } & Accipitridae & 32 & 18.75 \\
\hline & Cathartidae & 4 & 75.00 \\
\hline Euripygyformes & Eurypygidae & 1 & 0.00 \\
\hline \multirow[t]{5}{*}{ Gruiformes } & Aramidae & 1 & 0.00 \\
\hline & Cariamidae & 1 & 0.00 \\
\hline & Heliornithidae & 1 & 0.00 \\
\hline & Psophiidae & 3 & 33.33 \\
\hline & Rallidae & 36 & 19.44 \\
\hline \multirow[t]{6}{*}{ Charadriiformes } & Charadriidae & 4 & 0.00 \\
\hline & Jacanidae & 2 & 0.00 \\
\hline & Laridae & 4 & 0.00 \\
\hline & Pluvianellidae & 1 & 0.00 \\
\hline & Rostratulidae & 1 & 0.00 \\
\hline & Scolopacidae & 6 & 0.00 \\
\hline Columbiformes & Columbidae & 32 & 9.38 \\
\hline Opisthocomiformes & Opisthocomidae & 1 & 0.00 \\
\hline Strigiformes & Strigidae & 40 & 7.50 \\
\hline \multirow[t]{2}{*}{ Apodiformes } & Apodidae & 16 & 0.00 \\
\hline & Trochilidae & 300 & 10.67 \\
\hline \multirow[t]{3}{*}{ Caprimulgiformes } & Caprimulgidae & 22 & 0.00 \\
\hline & Nyctibiidae & 7 & 0.00 \\
\hline & Steatornithidae & 1 & 0.00 \\
\hline
\end{tabular}




\begin{tabular}{|c|c|c|c|}
\hline Order & Family & Species & Threatened\% \\
\hline Trogoniformes & Trogonidae & 5 & 0.00 \\
\hline \multirow[t]{2}{*}{ Coraciiformes } & Alcedinidae & 4 & 0.00 \\
\hline & Momotidae & 8 & 12.50 \\
\hline Galbuliformes & Bucconidae & 24 & 0.00 \\
\hline \multirow[t]{4}{*}{ Piciformes } & Capitonidae & 6 & 0.00 \\
\hline & Galbulidae & 13 & 15.38 \\
\hline & Picidae & 59 & 5.08 \\
\hline & Ramphastidae & 24 & 16.67 \\
\hline Falconiformes & Falconidae & 16 & 12.50 \\
\hline Psitaciformes & Psittacidae & 97 & 27.84 \\
\hline \multirow[t]{27}{*}{ Passeriformes } & Cardinalidae & 22 & 18.18 \\
\hline & Carduelidae & 22 & 13.64 \\
\hline & Conopophagidae & 5 & 0.00 \\
\hline & Corvidae & 12 & 0.00 \\
\hline & Cotingidae & 33 & 33.33 \\
\hline & Cuculidae & 17 & 5.88 \\
\hline & Emberizidae & 109 & 11.01 \\
\hline & Eurylaimidae & 1 & 0.00 \\
\hline & Formicariidae & 33 & 15.15 \\
\hline & Furnariidae & 170 & 8.24 \\
\hline & Hirundinidae & 17 & 23.53 \\
\hline & Icteridae & 48 & 14.58 \\
\hline & Mimidae & 6 & 0.00 \\
\hline & Motacillidae & 7 & 14.29 \\
\hline & Parulidae & 25 & 20.00 \\
\hline & Pipridae & 38 & 10.53 \\
\hline & Polioptilidae & 9 & 0.00 \\
\hline & Ptilogonatidae & 1 & 0.00 \\
\hline & Rhinocryptidae & 31 & 19.35 \\
\hline & Thamnophilidae & 126 & 19.84 \\
\hline & Thraupidae & 159 & 8.81 \\
\hline & Tityridae & 21 & 14.29 \\
\hline & Troglodytidae & 61 & 8.20 \\
\hline & Turdidae & 42 & 2.38 \\
\hline & Tyrannidae & 304 & 8.55 \\
\hline & Vireonidae & 28 & 7.14 \\
\hline & Total & 2268 & 12.17 \\
\hline
\end{tabular}




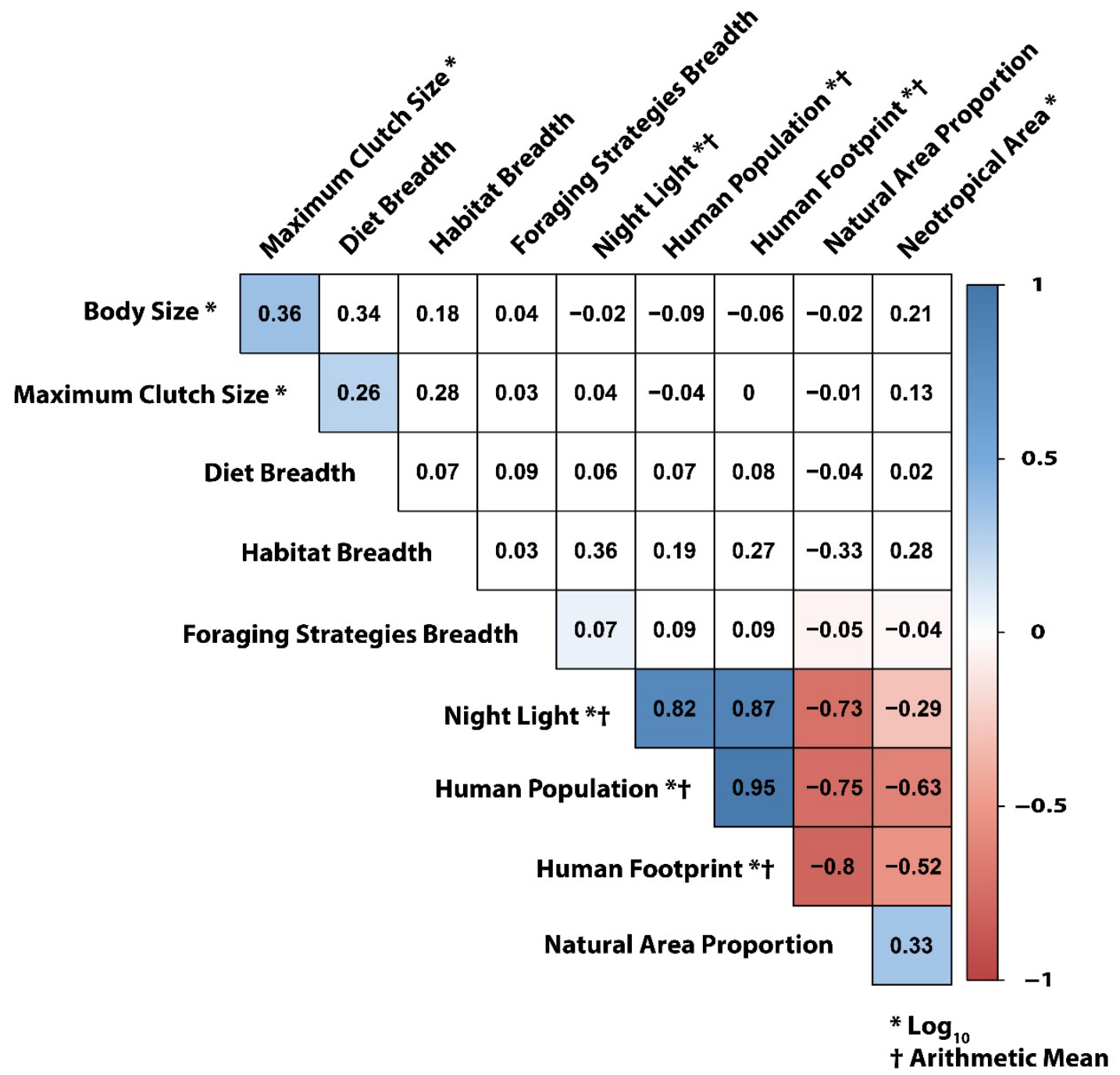

Figure A1.1. Pairwise Spearman's $r$ correlation values among tested predictors. Significant correlations $(p<0.05)$ are in coloured squares, with reds indicating negative correlations and blue positive associations. 


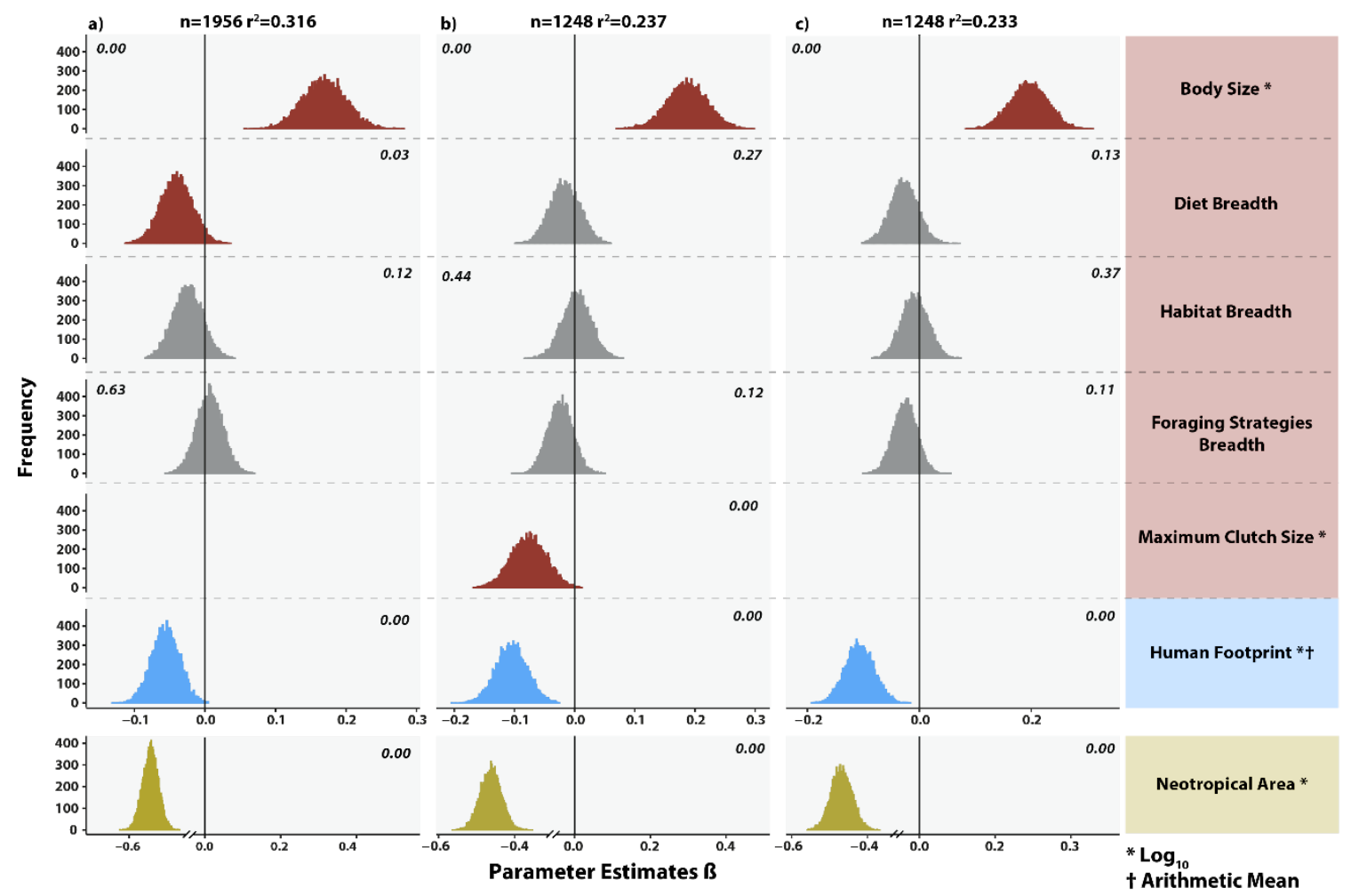

Figure A1.2. Posterior distribution of the coefficient parameters $(\beta)$ for tested intrinsic and extrinsic (represented by Human footprint here) variables associated with extinction risk (Red List status). Results for three fitted models: a) excluding maximum clutch size and using all species with data on remaining predictors (dataset C); b) full model (dataset B); c) model excluding maximum clutch size but using dataset $B$ (to test for collinearity issues). Numbers within panels indicate the proportion of estimates $(p)$ with sign equal from that of the median value 0 ( $p<0.1$ indicates support for an effect). 


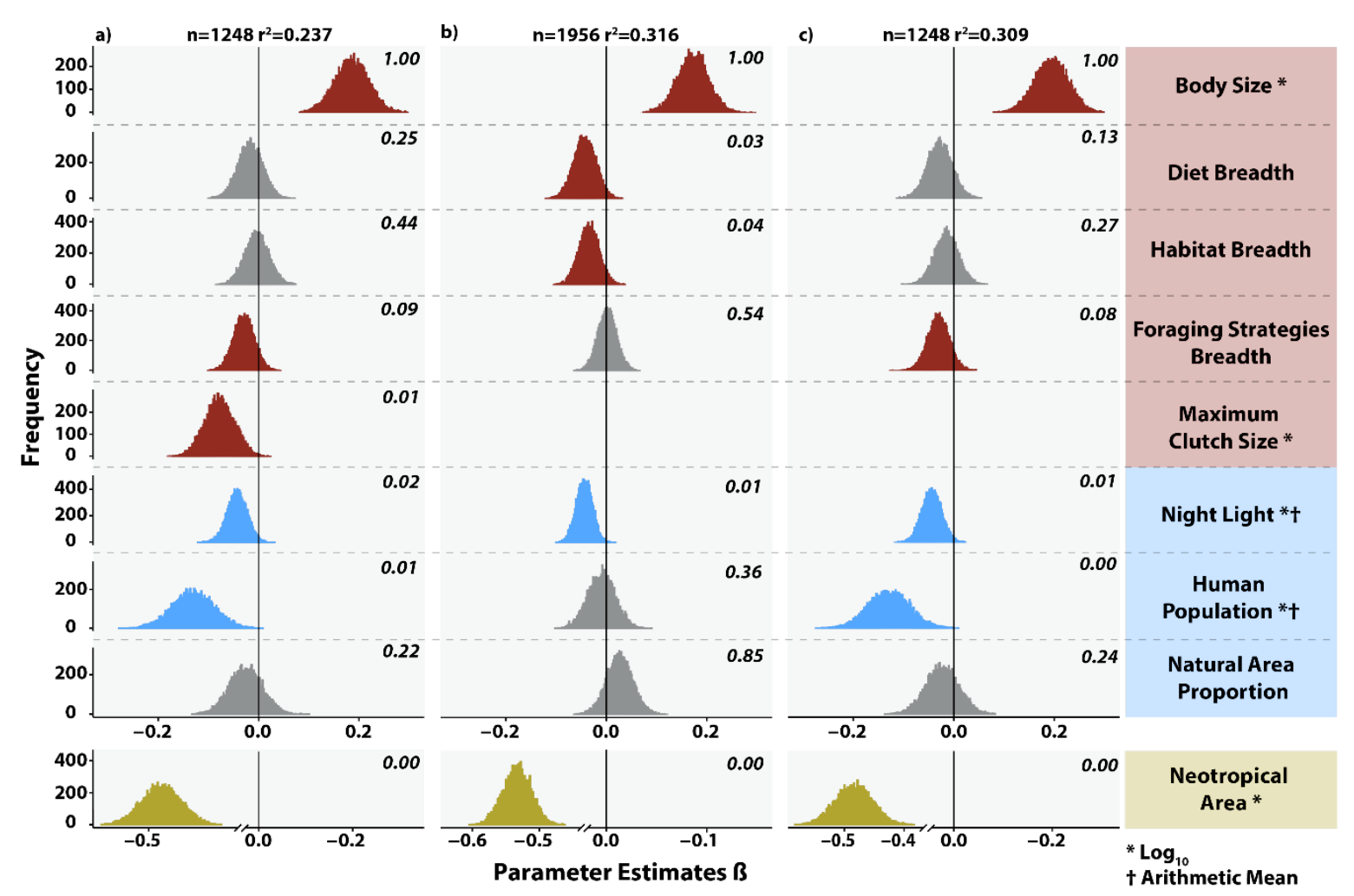

Figure A1.3. Model results showing the effects (posterior distribution of the regression slope, $\beta$ ) of different predictors in the response variable extinction risk (Red List status). Results represent three models fitting for: a) full model; b) excluding maximum clutch size and using all species with data on remaining predictors and $\mathrm{c}$ ) model excluding maximum clutch size but using dataset $\mathrm{B}$. Model fit described by estimated R2 is provided for each model. Small numbers between 0 and 1 within panels represent the support of each effect quantified by the proportion of estimates with sign equal from that of the median value. We considered $p<0.1$ (distributions shown with a red fill) indicates strong support for an effect. * $\log 10$-transformed variables. tvariables described as the arithmetic mean. 


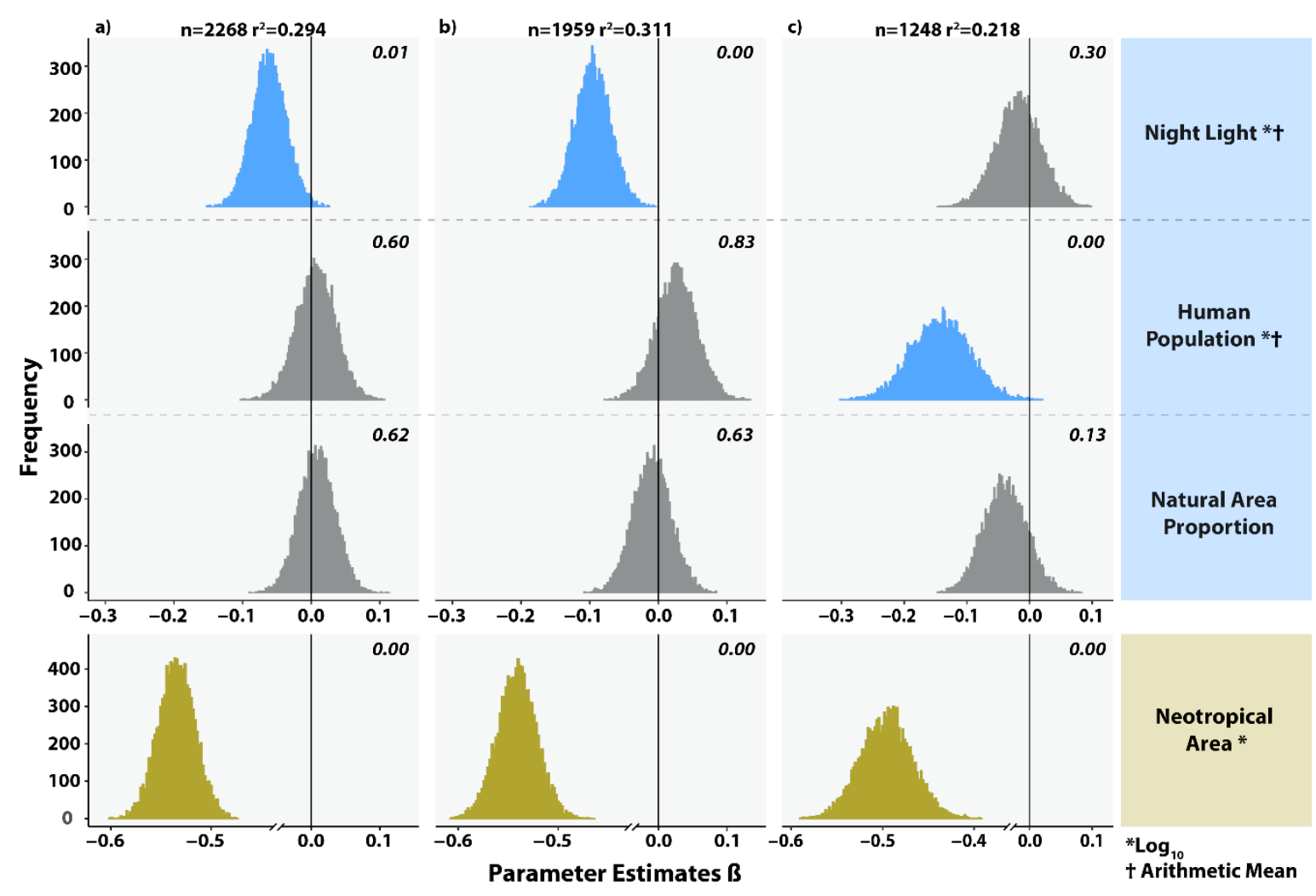

Figure A1.4 Model results showing the effects (posterior distribution of the regression slope, $\beta$ ) of extrinsic predictors in the response variable extinction risk (Red List status). Results represent three models fitting with data from 2268, 1959 and 1248 species respectively for: a) all species; b) excluding maximum clutch size and using all species with data on remaining predictors and c) species with data for all intrinsic and extrinsic variables. Model fit described by estimated R2 is provided for each model. Small numbers between 0 and 1 within panels represent the support of each effect quantified by the proportion of estimates with sign equal from that of the median value. We considered $p<0.1$ (distributions shown with a red fill) indicates strong support for an

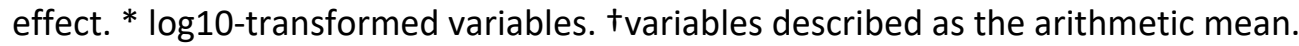



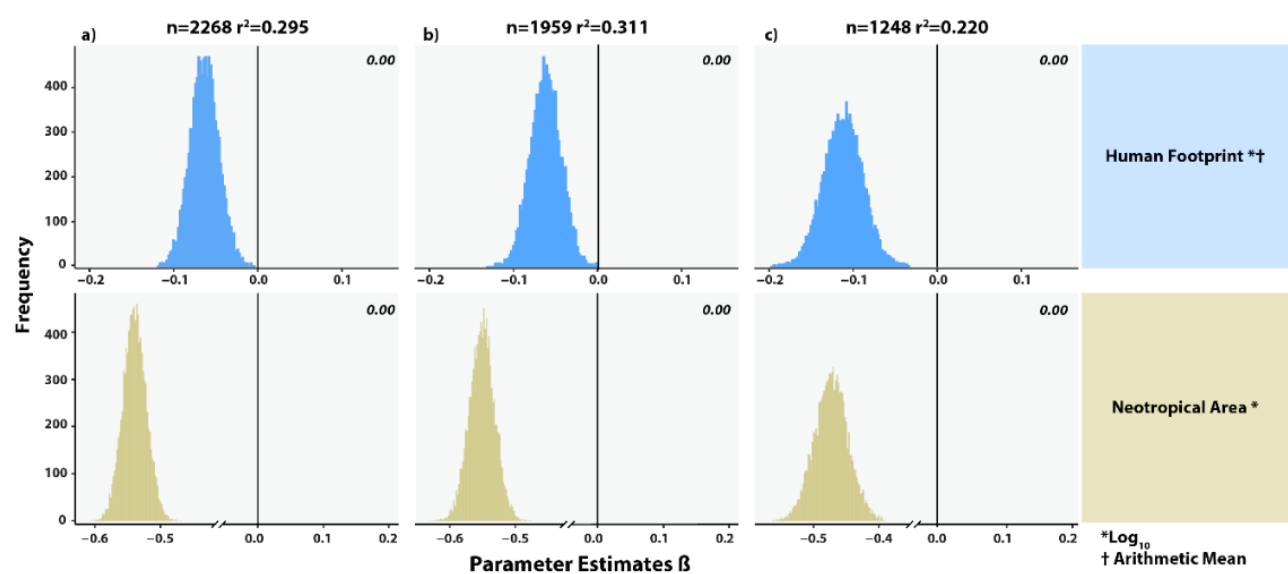

Figure A1.5. Model results showing the effects (posterior distribution of the regression slope, $\beta$ ) of Human footprint predictor in the response variable extinction risk (Red List status). Results represent three models fitting with data from 2268, 1959 and 1248 species respectively for: a) all species; b) excluding maximum clutch size and using all species with data on remaining predictors and c) species with data for all intrinsic and extrinsic variables. Model fit described by estimated $\mathrm{R} 2$ is provided for each model. Small numbers between 0 and 1 within panels represent the support of each effect quantified by the proportion of estimates with sign equal from that of the median value. We considered $p<0.1$ (distributions shown with a red fill) indicates strong support for an effect. * log10-transformed variables. tvariables described as the arithmetic mean. 


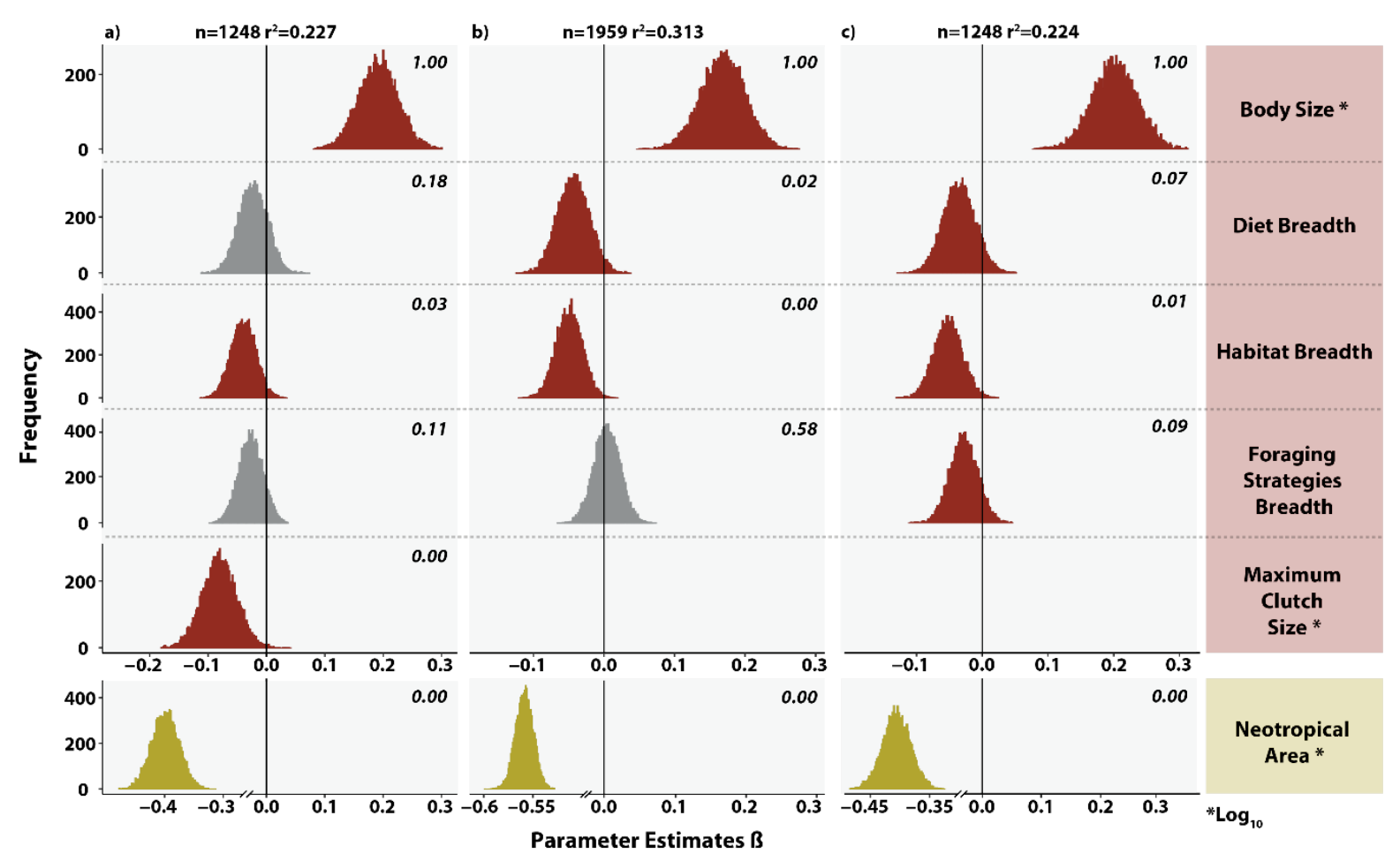

Figure A1.6. Model results showing the effects (posterior distribution of the regression slope, $\beta$ ) of intrinsic predictors in the response variable extinction risk (Red List status). Results represent three models fitting for: a) all species; b) excluding maximum clutch size and using all species with data on remaining predictors and c) species with data for all intrinsic and extrinsic variables. Model fit described by estimated R2 is provided for each model. Small numbers between 0 and 1 within panels represent the support of each effect quantified by the proportion of estimates with sign equal from that of the median value. We considered $p<0.1$ (distributions shown with a red fill) indicates strong support for an effect. ${ }^{*} \log 10$-transformed variables. tvariables described as the arithmetic mean. 


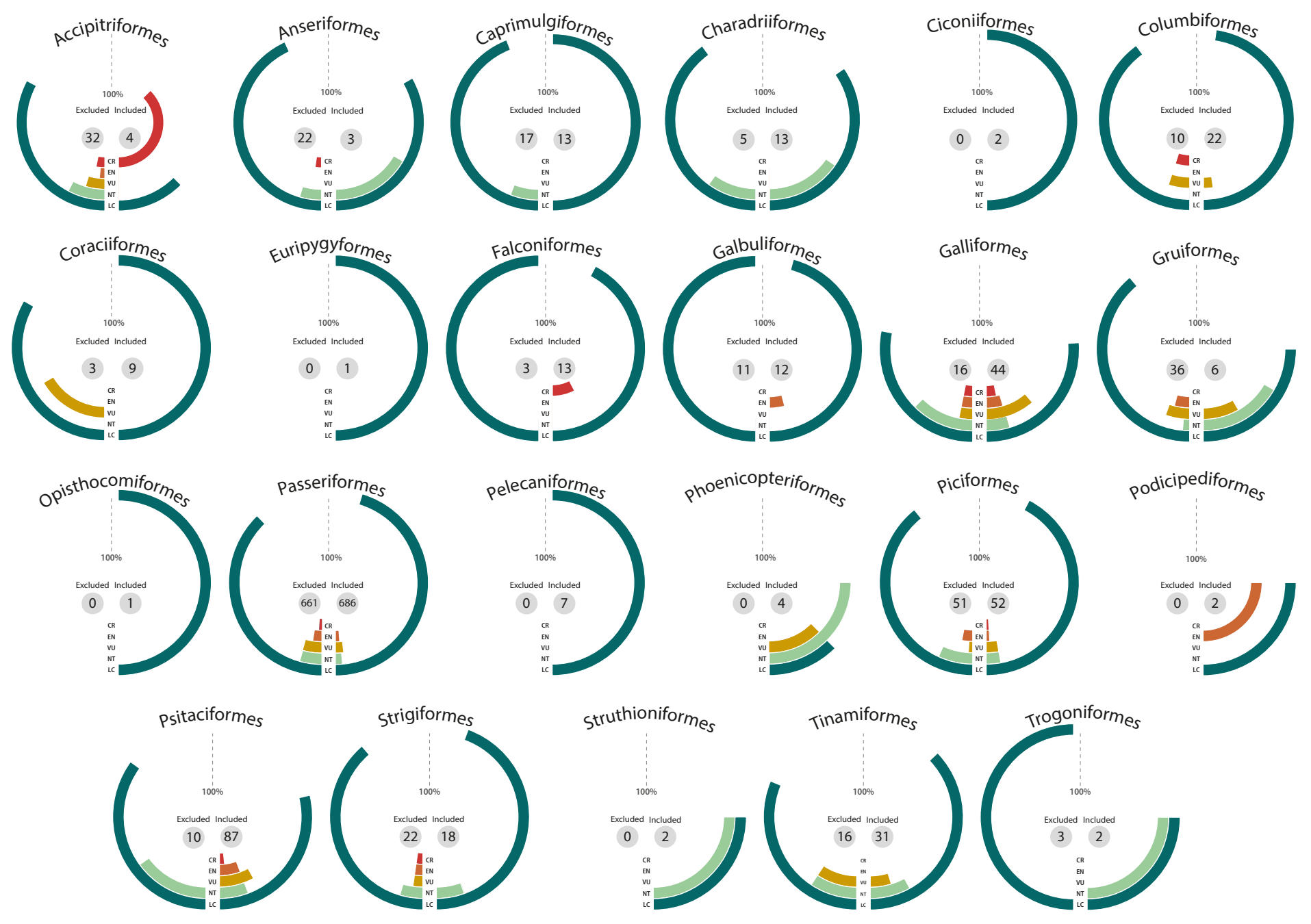

Figure A1.7. Percentage of species of each order included (Right bars) and excluded (Left bars) within the complete model and each of the IUCN Red List Categories. LC=Least Concern, NT= Near Threatened, VU= Vulnerable, EN=Endangered, CR=Critically Endangered. Grey circle indicates total numbers of species excluded and included. 


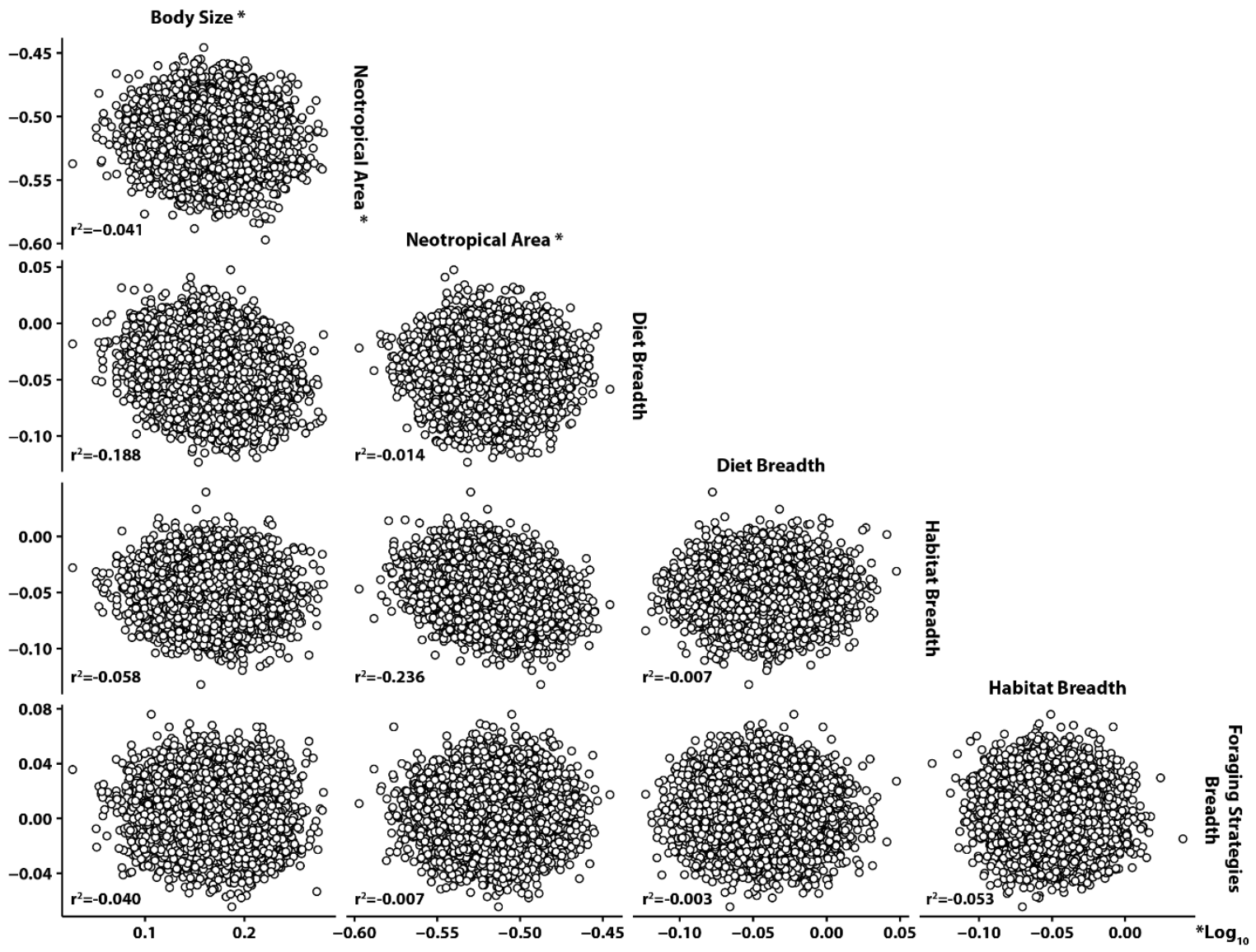

6. Figure A1.8. Correlation matrix plot using Spearman Correlation test with pairwise complete observations among beta parameters from Intrinsic Model (Fig 2a) using "cor" function in R ( R Development Core Team 2016).

7.

8.

9.

10.

11. 
12.
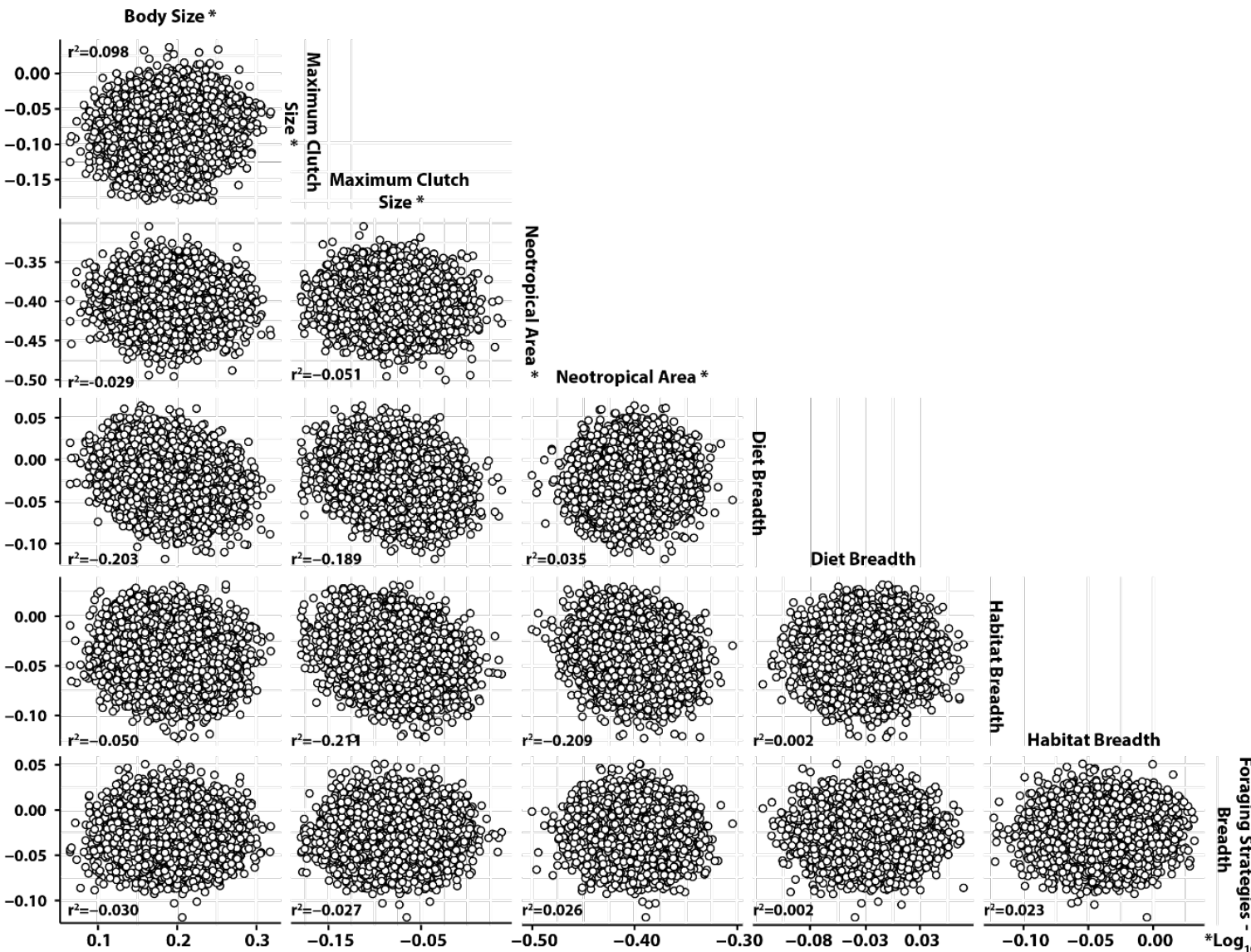

13.

14. Figure A1.9. Correlation matrix plot using Spearman Correlation test with pairwise complete observations among beta parameters from Intrinsic Model (Fig 2b) using "cor" function in R ( $R$ Development Core Team 2016).

15.

16. 


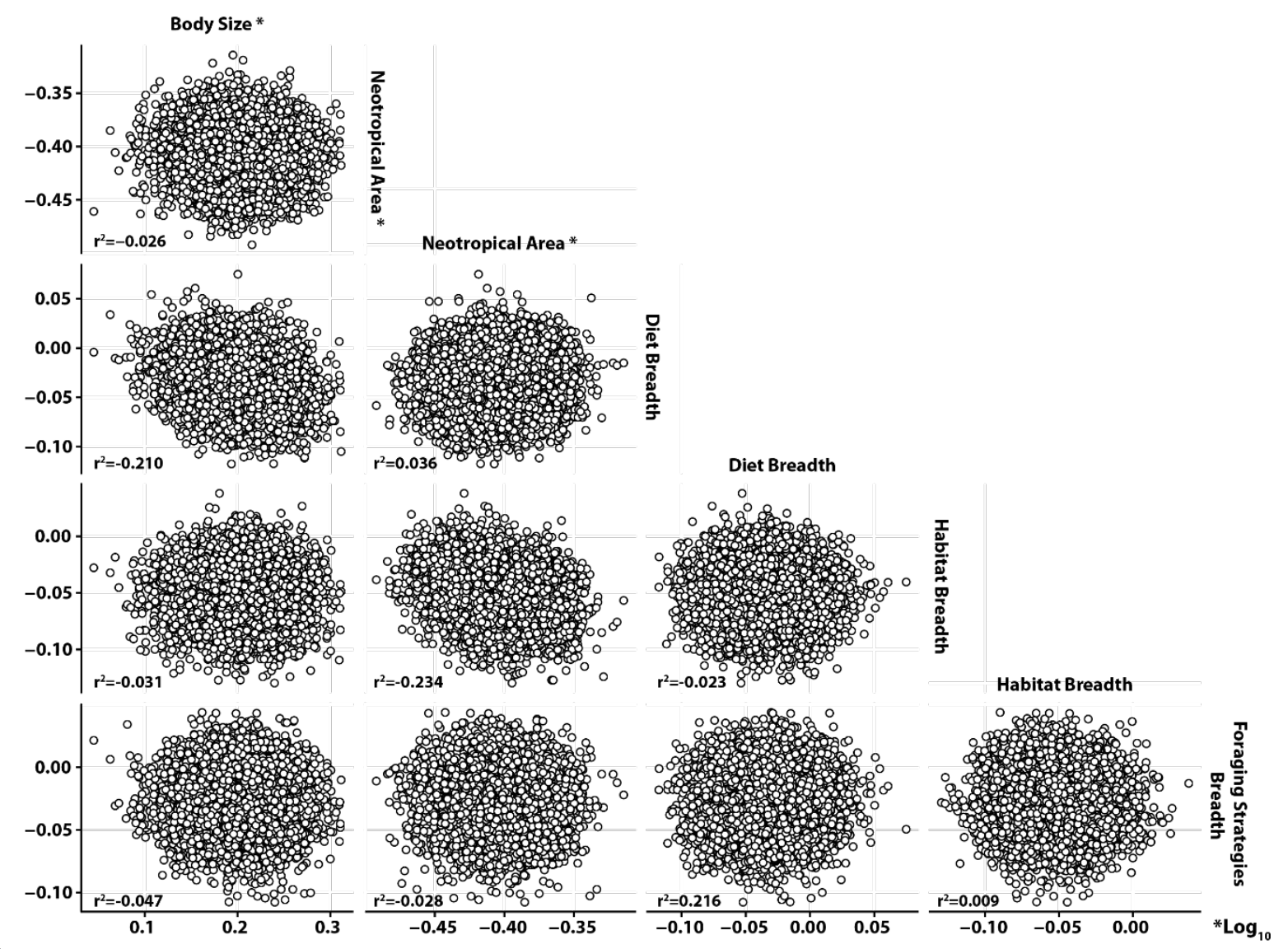

17.

18. Figure A1.10. Correlation matrix plot using Spearman Correlation test with pairwise complete observations among beta parameters from Intrinsic Model (Fig 2c) using "cor" function in R (R Development Core Team 2016). MI3

19.

20. 


\section{References}

Billerman, S. M., B. K. Keeney, P. G. Rodewal, and T. S. Schulenberg. 2020. Birds of the World. Cornell Laboratory of Ornithology. Ithaca, NY, USA. https://birdsoftheworld.org/bow/home.

BirdLife International. 2020. IUCN Red List for birds: distribution maps. http://www.birdlife.org/.

Ellis, E. C., and N. Ramankutty. 2008. Putting people in the map: anthropogenic biomes of the world. Frontiers in Ecology and the Environment 6:439-447. doi: 10.1890/070062.

ESRI. 2014. Environmental Systems Research Institute (ESRI). Redlands, CA, USA.

Levins, R. 1968. Evolution in Changing Environments: Some Theoretical Explorations, 1st edition. Princeton University Press.

NOAA. 2017. Average Visible, Stable Lights, \& Cloud Free Coverages 2013. Image and data processing by NOAA's National Geophysical Data Center. DMSP data collected by US Air Force Weather Agency. https://ngdc.noaa.gov/eog/data/web_data/v4composites/F182013.v4.tar.

Quantum GIS Development Team. 2017. Quantum GIS Geographic Information System. Open Source Geospatial Foundation Project.

R Development Core Team. 2016. R: A Language and Environment for Statistical Computing. $R$ Foundation for Statistical Computing Vienna Austria 0:\{ISBN\} 3-900051-07-0. doi:

10.1038/sj.hdy.6800737.

Wickham, H. 2007. Reshaping Data with the reshape Package. Journal of Statistical Software 21:120.

Wilman, H., J. Belmaker, J. Simpson, C. de la Rosa, M. M. Rivadeneira, and W. Jetz. 2014. EltonTraits 1.0: Species-level foraging attributes of the world's birds and mammals. Ecology 95:2027-2027. doi: 10.1890/13-1917.1. 